\title{
Comparison of ambient aerosol extinction coefficients obtained from in-situ, MAX-DOAS and LIDAR measurements at Cabauw
}

\author{
P. Zieger ${ }^{1}$, E. Weingartner ${ }^{1}$, J. Henzing ${ }^{2}$, M. Moerman ${ }^{2}$, G. de Leeuw ${ }^{2,3,4}$, J. Mikkilä ${ }^{4}$, M. Ehn ${ }^{4}$, T. Petäjä ${ }^{4}$,

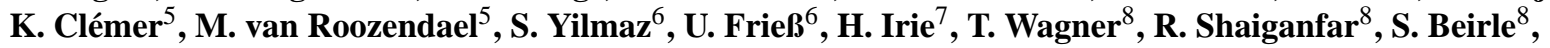 \\ A. Apituley ${ }^{9,10}$, K. Wilson ${ }^{9,10}$, and U. Baltensperger ${ }^{1}$ \\ ${ }^{1}$ Paul Scherrer Institut, Laboratory of Atmospheric Chemistry, 5232 Villigen, Switzerland \\ ${ }^{2}$ Netherlands Organization for Applied Scientific Research TNO, Princetonlaan 6, 3508 Utrecht, The Netherlands \\ ${ }^{3}$ Finnish Meteorological Institute, Climate Change Unit, Erik Palmenin Aukio 1, 00101 Helsinki, Finland \\ ${ }^{4}$ University of Helsinki, Department of Physics, Gustaf Hällströmin katu 2, 00014 Helsinki, Finland \\ ${ }^{5}$ Belgium Institute for Space Aeronomy, Ringlaan 3, 1180 Brussels, Belgium \\ ${ }^{6}$ University of Heidelberg, Institute of Environmental Physics, Im Neuenheimer Feld 229, 69120 Heidelberg, Germany \\ ${ }^{7}$ Japan Agency for Marine-Earth Science and Technology, Research Institute for Global Change, Yokohama, Japan \\ ${ }^{8}$ Max-Planck-Institute for Chemistry, Joh.-Joachim-Becher-Weg 27, 5512 Mainz, Germany \\ ${ }^{9}$ National Institute for Public Health and the Environment RIVM, 3721 Bilthoven, The Netherlands \\ ${ }^{10}$ Royal Netherlands Meteorological Institute KNMI, 3730 AE De Bilt, The Netherlands
}

Received: 1 November 2010 - Published in Atmos. Chem. Phys. Discuss.: 6 December 2010

Revised: 14 February 2011 - Accepted: 11 March 2011 - Published: 18 March 2011

\begin{abstract}
In the field, aerosol in-situ measurements are often performed under dry conditions (relative humidity $\mathrm{RH}<30$ $40 \%$ ). Since ambient aerosol particles experience hygroscopic growth at enhanced RH, their microphysical and optical properties - especially the aerosol light scattering are also strongly dependent on RH. The knowledge of this $\mathrm{RH}$ effect is of crucial importance for climate forcing calculations or for the comparison of remote sensing with insitu measurements. Here, we will present results from a four-month campaign which took place in summer 2009 in Cabauw, The Netherlands. The aerosol scattering coefficient $\sigma_{\text {sp }}(\lambda)$ was measured dry and at various, predefined RH conditions between 20 and $95 \%$ with a humidified nephelometer. The scattering enhancement factor $f(\mathrm{RH}, \lambda)$ is the key parameter to describe the effect of RH on $\sigma_{\mathrm{sp}}(\lambda)$ and is defined as $\sigma_{\mathrm{sp}}(\mathrm{RH}, \lambda)$ measured at a certain $\mathrm{RH}$ divided by the dry $\sigma_{\mathrm{sp}}(\mathrm{dry}, \lambda)$. The measurement of $f(\mathrm{RH}, \lambda)$ together with the dry absorption measurement (assumed not to change with $\mathrm{RH})$ allows the determination of the actual extinction coefficient $\sigma_{\mathrm{ep}}(\mathrm{RH}, \lambda)$ at ambient $\mathrm{RH}$. In addition, a wide range of other aerosol properties were measured in parallel. The measurements were used to characterize the effects of RH on the
\end{abstract}

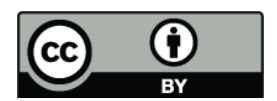

Correspondence to: E. Weingartner (ernest.weingartner@psi.ch) aerosol optical properties. A closure study showed the consistency of the aerosol in-situ measurements. Due to the large variability of air mass origin (and thus aerosol composition) a simple parameterization of $f(\mathrm{RH}, \lambda)$ could not be established. If $f(\mathrm{RH}, \lambda)$ needs to be predicted, the chemical composition and size distribution need to be known. Measurements of four MAX-DOAS (multi-axis differential optical absorption spectroscopy) instruments were used to retrieve vertical profiles of $\sigma_{\mathrm{ep}}(\lambda)$. The values of the lowest layer were compared to the in-situ values after conversion of the latter ones to ambient $\mathrm{RH}$. The comparison showed a good correlation of $R^{2}=0.62-0.78$, but the extinction coefficients from MAX-DOAS were a factor of 1.5-3.4 larger than the insitu values. Best agreement is achieved for a few cases characterized by low aerosol optical depths and low planetary boundary layer heights. Differences were shown to be dependent on the applied MAX-DOAS retrieval algorithm. The comparison of the in-situ extinction data to a Raman LIDAR (light detection and ranging) showed a good correlation and higher values measured by the LIDAR $\left(R^{2}=0.82-0.85\right.$, slope of 1.69-1.76) if the Raman retrieved profile was used to extrapolate the directly measured extinction coefficient to the ground. The comparison improved if only nighttime measurements were used in the comparison $\left(R^{2}=0.96\right.$, slope of 1.12).

Published by Copernicus Publications on behalf of the European Geosciences Union. 


\section{Introduction}

Atmospheric aerosol particles change in size due to water uptake which is determined by their chemical composition and the ambient relative humidity (RH). As a result their optical properties - especially the aerosol light scattering also strongly depend on RH. Therefore, long-term measurements of aerosol physical and optical properties are generally recommended at dry conditions in order to keep measurements comparable (e.g. $\mathrm{RH}<30-40 \%$ as recommended by WMO/GAW, 2003). However, for the comparison of such ground-based measurements with other optical aerosol measurements (e.g. LIDAR, MAX-DOAS or satellite retrieval), for the purpose of aerosol correction of satellite retrievals, or for the use in climate models, accurate knowledge of the $\mathrm{RH}$ effect is very important.

The size and the solubility of a particle determine the response of an ambient particle to changes in RH. The water vapor pressure above a water droplet containing dissolved material is lowered by the Raoult effect. The equilibrium size of a droplet was first described by Köhler (1936), who considered the Kelvin (curvature) and Raoult (solute) effect. The growth of an aerosol particle due to water uptake is described by the hygroscopic growth factor $g(\mathrm{RH})$ which is defined as the particle diameter $D_{\text {wet }}$ at a certain RH divided by its dry diameter $D_{\text {dry }}$ :

$g(\mathrm{RH})=\frac{D_{\mathrm{wet}}(\mathrm{RH})}{D_{\mathrm{dry}}}$.

The RH dependence of $g(\mathrm{RH})$ can be parameterized in a good approximation by a one-parameter equation, proposed e.g. by Petters and Kreidenweis (2007):

$g\left(a_{\mathrm{w}}\right)=\left(1+\kappa \frac{a_{\mathrm{w}}}{1-a_{\mathrm{w}}}\right)^{\frac{1}{3}}$.

Here, $a_{\mathrm{w}}$ is the water activity, which can be replaced by the relative humidity RH, if the Kelvin effect is negligible, as for particles with sizes more relevant for light scattering and absorption, i.e. with $D_{\text {wet }}>100 \mathrm{~nm}$. The coefficient $\kappa$ is a simple measure of the particle's hygroscopicity and captures all solute properties (Raoult effect). The impact of hygroscopic growth on the aerosol light scattering coefficient is usually described by the scattering enhancement factor $f(\mathrm{RH}, \lambda)$ :

$f(\mathrm{RH}, \lambda)=\frac{\sigma_{\mathrm{sp}}(\mathrm{RH}, \lambda)}{\sigma_{\mathrm{sp}}(\operatorname{dry}, \lambda)}$,

where the scattering coefficient $\sigma_{\mathrm{sp}}$ depends on the wavelength $\lambda$ and the relative humidity RH. In the following we will discuss the characteristics of the scattering enhancement factor for $\lambda=550 \mathrm{~nm}$. Since no clear wavelength dependency was found during our measurement period (in the range of $450-700 \mathrm{~nm}$ ), we will omit $\lambda$ for simplicity and refer to the scattering enhancement factor as $f(\mathrm{RH})$.
Measured and modeled enhancement factors have been described in several previous studies, including studies on urban (Yan et al., 2009; Fitzgerald et al., 1982), continental (Sheridan et al., 2001), biomass burning (Kotchenruther and Hobbs, 1998), maritime (Fierz-Schmidhauser et al., 2010b; Wang et al., 2007; Carrico et al., 2003), free tropospheric (Fierz-Schmidhauser et al., 2010a; Nessler et al., 2005a) or Arctic aerosol (Zieger et al., 2010).

The comparison of remote sensing measurements to insitu values of the aerosol extinction coefficient for validation purposes has been performed in several studies. Lidar measurements have been compared to nephelometer measurements, but almost always with dry nephelometer data using model assumptions or literature values of $f(\mathrm{RH})$ (Ferrare et al., 1998; Voss et al., 2001) and only rarely using a humidified nephelometer (Morgan et al., 2010). The MAX-DOAS technique for aerosol retrieval is novel and only few comparisons have been made with in-situ data. The first comparison of the extinction coefficient (measured at Ghuangzhou, China) with a single MAX-DOAS instrument (similar retrieval as for the instrument by the Max-Planck-Institute for Chemistry (MPI), see below) to nephelometer data was made by $\mathrm{Li}$ et al. (2010) using a single parameterization from a different station ( $60 \mathrm{~km}$ further away) to calculate the ambient aerosol extinction coefficients from the dry nephelometer data. In addition, they only used ground based RH measurements and differences between indoor and ambient RH and temperature conditions were not accounted for.

In this study, the RH dependency of the aerosol extinction coefficient was examined using direct measurements of aerosol optical properties as a function of RH taken during a four months' campaign at Cabauw, The Netherlands. The data were compared in an optical closure study with Miecalculations, which relied on the aerosol number size distribution corrected to a specific RH using hygroscopicity measurements. As a proof of concept, the in-situ measurements of the aerosol extinction coefficient were compared to remote sensing data from MAX-DOAS and LIDAR measurements. The vertical profiles of the aerosol extinction coefficient obtained from MAX-DOAS and their comparison to LIDAR measurements are discussed in an upcoming publication (Frieß et al., 2011).

\section{The Cabauw site and the CINDI campaign}

A field campaign was carried out from 8 June to 6 October 2009 at the Cabauw Experimental Site for Atmospheric Research (CESAR, located at $51.97^{\circ} \mathrm{N}, 4.93^{\circ} \mathrm{E}$ ) in The Netherlands. The site is located approximately $33 \mathrm{~km}$ north-east of the city of Rotterdam and $30 \mathrm{~km}$ south-west of Utrecht. CESAR is a facility dedicated to the observation and characterization of the state of the atmosphere, its radiative properties and interaction with land surface, for the study of physical processes, climate monitoring and 
validation studies (Russchenberg et al., 2005). A large set of continuous in-situ and remote sensing equipment is installed at the site. A $213 \mathrm{~m}$ high mast equipped with various meteorological sensors (like temperature, dew point, wind direction, wind speed, etc.) is the main feature of the CESAR site. The continuous aerosol measurements are contributing to the EUSAAR (European Supersites for Atmospheric Aerosol Research) project (Philippin et al., 2009) with associated quality control, site audits, and reporting.

During 16 June and 24 July 2009 our measurements were part of the CINDI campaign (Cabauw Intercomparison Campaign of Nitrogen Dioxide measuring Instruments) where the main goal was to compare different remote sensing and in-situ techniques measuring $\mathrm{NO}_{2}$. Besides $\mathrm{NO}_{2}$, other atmospheric gases and aerosols were measured and intercompared. For more details see Roscoe et al. (2010) and Piters et al. (2010).

\section{Experimental}

Various physical aerosol properties have been measured during the four-month period. The following section describes the main experimental techniques used in this work. In the first part (Sect. 3.1) the main in-situ instruments used to characterize the effects of $\mathrm{RH}$ on the aerosol extinction coefficient will be described. The results of the insitu measurements are later compared to two different atmospheric profiling techniques: First to MAX-DOAS measurements (Sect. 3.2) and in a next step to LIDAR measurements (Sect. 3.3). This comparison is carried out only for the lowest ground layer.

\subsection{In-situ measurements}

\subsubsection{Inlet system}

Air is sampled at a height of $60 \mathrm{~m}$ at the Cabauw tower. The inlet system consists of four parts: (a) $\mathrm{PM}_{10}$ size selective inlets (4 $\mathrm{PM}_{10}$ heads), (b) a Nafion drying system that dries aerosol to or below $40 \% \mathrm{RH}$, (c) a 60-m stainless steel pipe, and (d) a manifold that splits the flow to the suite of instruments. The manifold and the in-situ instruments are all located at the basement of the tower. The in-situ measurements used in this paper are those from the nephelometer, the multiangle absorption photometer (MAAP), the aethalometer, the scanning mobility particle sizer (SMPS) and aerodynamic particle sizer (APS), all of which are described below. These instruments sampled their flow from the manifold using separate pumps to adjust the required flow for proper operation of the instruments.

The total flow sustained in the $60-\mathrm{m}$ inlet pipe was $60 \mathrm{lpm}$, for optimal operation of the $\mathrm{PM}_{10}$ inlets. Whenever an instrument was added or removed, the flows to the other instruments were checked and adjusted when needed. Although attempts have been made to characterize the losses, they were not conclusive in an experimental sense. In general the losses in similar inlet pipes can be calculated by theory (e.g., Birmili et al., 2007). Losses through diffusion (for smaller particles with $D<0.1 \mu \mathrm{m}$ ) and sedimentation (for larger particles with $D>2 \mu \mathrm{m}$ ) are expected to be below 10-20\%. Since the main contribution to the extinction in the visible nephelometer wavelength will be in the size range between 0.1 and $1 \mu \mathrm{m}$, the effect of particle losses on the dry extinction coefficient is assumed to be smaller than $10-20 \%$. Additional losses are expected due to the use of a Nafion dryer but there is no quantitative information for the specific dryer used in Cabauw.

\subsubsection{Humidified and dry nephelometer}

A recently developed humidified nephelometer (WetNeph) was installed for four months next to the continuously running aerosol in-situ instruments. The WetNeph is described in detail by Fierz-Schmidhauser et al. (2010c). Briefly, the aerosol scattering coefficient $\sigma_{\mathrm{sp}}(\lambda)$ and the back scattering coefficient $\sigma_{\mathrm{bsp}}(\lambda)$ are measured at three wavelengths $(\lambda=450,550$, and $700 \mathrm{~nm})$ at defined RH between $20 \%$ and $95 \%$. For this purpose a specifically designed single-stream humidification system (consisting of a humidifier followed by a dryer) brings the initially dry aerosol (the aerosol is already dried at the main inlet) to a defined RH before its scattering properties are measured by an integrating nephelometer (TSI Inc., Model 3563).

The WetNeph was programmed to measure RH cycles. In the first part of the cycle, the dry particles experience elevated RH in the humidifier, after which they are passed through the turned off dryer before their scattering properties are measured in the nephelometer (hydration mode). It is noted that the temperature in the nephelometer's detection cell is $\sim 1^{\circ} \mathrm{C}$ higher than in the humidifier, thereby causing a slight RH decrease of approximately $2-6 \%$ (see Fig. A1 in Fierz-Schmidhauser et al., 2010c) and with that a concurrent shift of the observed deliquescence RH. Deliquescence is described as a sudden uptake of water of an initially dry and solid particle at the defined deliquescence relative humidity. Inorganic salts (for instance ammonium sulfate or sodium chloride) exhibit a distinct deliquescence. Organic constituents of mixed atmospheric aerosols can suppress the deliquescence of inorganic salts (Sjogren et al., 2007). The behavior of dehydrating particles following the upper hysteresis branch of the growth curve is measured by setting the humidifier to its maximum $\mathrm{RH}$ ( $\sim 95 \%)$, followed by $\mathrm{RH}$ reduction in the dryer and measurement in the nephelometer (dehydration mode). The lowest possible RH in this mode was $\sim 55 \%$, limited by the capacity of the dryer at the high sample flow of $101 \mathrm{~min}^{-1}$ chosen for this campaign. The RH inside the nephelometer cell is monitored by a HygroClip (Rotronic), which was calibrated before and after the campaign with standard salt solutions, and in addition by a dew point mirror (Edge Tech, Model 2000, Dewprime DF). More 
technical details can be found in Fierz-Schmidhauser et al. (2010c).

A second nephelometer (DryNeph, TSI Inc., Model 3563, operated by TNO) was used in parallel to measure the scattering coefficient under dry conditions as a reference. The RH inside the DryNeph was always below $30 \%$ (campaign mean $\mathrm{RH}=17.7 \%$ ).

Both nephelometers measured within the scattering angles of $7^{\circ}$ to $170^{\circ}$. The scattering coefficients for the complete angle between $0^{\circ}$ and $180^{\circ}$ were retrieved by correcting the measured values using the scheme proposed by Anderson et al. (1996) (truncation error correction) which also accounts for non-idealities of the light source in the nephelometer.

Both nephelometers were calibrated (with particle-free air and $\mathrm{CO}_{2}$ ) and compared directly (WetNeph without humidifier system). In addition, the scattering coefficients at dry conditions $\left(\mathrm{RH}_{\mathrm{WetNeph}}<40 \%\right)$ were compared for the entire campaign. From these measurements it was found that the WetNeph scattering coefficients at dry conditions were slightly higher than the ones of the DryNeph (for $450 \mathrm{~nm}: \quad \sigma_{\text {WetNeph }}=1.07 \sigma_{\text {DryNeph }}+8.7 \times 10^{-7} \mathrm{~m}^{-1}$, $R^{2}=0.99 ;$ for $550 \mathrm{~nm}: \sigma_{\text {WetNeph }}=1.06 \sigma_{\text {DryNeph }}+6.7 \times$ $10^{-7} \mathrm{~m}^{-1}, R^{2}=0.97$; for $700 \mathrm{~nm}: \sigma_{\text {WetNeph }}=1.03 \sigma_{\text {DryNeph }}+$ $4.5 \times 10^{-7} \mathrm{~m}^{-1}, R^{2}=0.94$ ), which was caused by differences in the absolute calibration of the nephelometer (WetNeph nephelometer measured higher scattering coefficients) and losses in the humidifier ( $\sim 5 \%$, see Fierz-Schmidhauser et al. 2010c). The WetNeph measurements were therefore corrected accordingly.

\subsubsection{Measurement of the aerosol absorption coefficient}

A multi-angle absorption photometer (MAAP) and an aethalometer were used to quantify the aerosol absorption properties.

The MAAP (Thermo Scientific Inc., Model 5012, operated by TNO) measures the light attenuation and light scattered back from aerosol particles which are deposited on a filter. The measurement is performed at $\lambda=637 \mathrm{~nm}$ (which differs from the manufacturer's value of $670 \mathrm{~nm}$, Müller et al., 2010). A radiative transfer scheme is applied to retrieve the fraction of light absorbed by the deposited aerosol (Petzold and Schönlinner, 2004). The aerosol absorption coefficient $\sigma_{\text {ap }}$ is obtained by multiplying the measured black carbon (BC) mass concentration with the instrumental set value of the mass absorption cross section of $6.6 \mathrm{~m}^{2} \mathrm{~g}^{-1}$.

In addition, an aethalometer (Magee Scientific, Model AE31, operated by RIVM) was used which measures the light attenuation by the aerosol particles (also deposited on a filter) at 7 wavelengths $(\lambda=370,470,520,590,660,880$, and $950 \mathrm{~nm})$. The aerosol absorption coefficient $\sigma_{\mathrm{ap}}(\lambda)$ is then derived from the light attenuation:

$\sigma_{\mathrm{ap}}(\lambda)=\frac{A}{Q} \frac{\triangle \mathrm{ATN}(\lambda)}{\Delta t} \frac{1}{C \cdot R(\mathrm{ATN}(\lambda))}$, where $A$ is the filter spot area, $Q$ the volumetric flow, and $\triangle \operatorname{ATN}(\lambda)$ the change of light attenuation during the time interval $\Delta t$ (Weingartner et al., 2003). The empirical constant $C$ corrects for multiple scattering in the unloaded filter. Here, a value of $C=4.09$ was used (Collaud Coen et al., 2010). The wavelength and ATN dependent factor $R$ corrects for effects caused by the amount of particles deposited on the filter, which decrease the optical path in the filter (also called the shadowing effect). $R$ was set to unity as the single scattering albedo $\omega_{0}$ (defined as the ratio of scattering to extinction coefficient) is larger than 0.8 most of the time (Weingartner et al., 2003).

Since the aethalometer measures at various wavelengths, the absorption Ångström exponent $\alpha_{\text {ap }}$ can be derived:

$\sigma_{\text {ap }}(\lambda)=\epsilon \lambda^{-\alpha_{\text {ap }}}$,

where $\lambda$ is the wavelength of the aethalometer and $\epsilon$ a concentration dependent constant.

Using the measured $\alpha_{\text {ap }}$ of the aethalometer and the measured value of $\sigma_{\mathrm{ap}}(637 \mathrm{~nm})$ from the MAAP, the absorption coefficient for a different wavelength $\lambda$ was calculated as follows:

$\sigma_{\text {ap }}(\lambda)=\sigma_{\text {ap }}(637 \mathrm{~nm})\left(\frac{\lambda}{637 \mathrm{~nm}}\right)^{-\alpha_{\mathrm{ap}}}$.

\subsubsection{Measurement of the aerosol size distribution}

A scanning mobility particle sizer (SMPS) and an aerodynamic particle sizer (APS) were used to measure the aerosol size distribution for dry diameters between approximately $10 \mathrm{~nm}$ and $5 \mu \mathrm{m}$ (both operated by TNO).

The SMPS (a modified TSI Inc., Model 3034) consists of a bipolar particle charger, a differential mobility analyzer (DMA) and a condensation particle counter (CPC). Particles are charged before they are classified in the DMA according to their electrical mobility diameter and are counted by the CPC. A correction for multiple charged particles was applied. Number size distributions in the diameter range between approximately 10 and $520 \mathrm{~nm}$ were recorded with a time resolution of $5 \mathrm{~min}$.

The APS (TSI Inc., Model 3321) measures the particle size distribution between aerodynamic diameters of approximately 0.5 and $20 \mu \mathrm{m}$. However, in Cabauw, particles larger than approximately $5 \mu \mathrm{m}$ are not sampled through the inlet system due to the $\mathrm{PM}_{10}$ size cut at the inlet and the drying thereafter, which results in a reduction in size. One distribution is recorded each minute.

The overlap between the SMPS and APS showed to be good for most of the cases. Small differences seen in the transition of the volume size distribution were caused by variations in density and shape influencing the APS sizing. However, they were found to be negligible for our purposes, since the scattering coefficient is dominated by contributions from the fine mode $\left(D_{p}<500 \mathrm{~nm}\right.$, measured by the SMPS). The 
measured volume size distributions could be well fitted using a three modal lognormal size distribution equation.

\subsubsection{Measurement of the hygroscopic growth factor}

Hygroscopic particles are able to grow in size by absorbing water vapor even at sub-saturated conditions. A simple way to describe the hygroscopicity of a particle is via the diameter growth factor $g(\mathrm{RH})$ as defined in Eq. (1). This property can be measured directly with a hygroscopicity tandem differential mobility analyzer (H-TDMA, Liu et al., 1978). The aerosol sample is first dried in the H-TDMA, and then charged with a bipolar charger. Subsequently a dry size class of particles, $D_{\text {dry }}$, is selected using a DMA (Winklmayr et al., 1991). At Cabauw, the H-TDMA of the University of Helsinki (modified version of the instrument presented by Ehn et al., 2007) was set up to measure $D_{\text {dry }}$ of $35,50,75$, 110 , and $165 \mathrm{~nm}$. Then the monodisperse particles are exposed to controlled relative humidity $(90 \%)$ and temperature. The wet aerosol goes through the second DMA, which scans a size range covering possible growths factors from 0.7 to 2.5. A corresponding concentration for each size fraction is monitored with a CPC. A humidified size distribution for a certain $D_{\text {dry }}$ is then obtained. The growth factors in this study were determined within \pm 0.05 , which is typical for a well-maintained TDMA system (Swietlicki et al., 2008).

In a complex location such as Cabauw, with several different aerosol sources, the particles are typically externally mixed. This is reflected in the hygroscopic growth factor spectrum by a widened distribution, or even by clearly separated growth modes, for a given particle size. The piecewise linear method of the TDMAinv Toolkit (Gysel et al., 2009) was used to retrieve the growth factor distributions. Although many different sources can contribute to the aerosol population, typically one of the sources dominated. Therefore, simply using the average growth factor for each distribution is sufficient to describe the temporal variation of the growth of the accumulation mode particles at $90 \% \mathrm{RH}$. In this work only the data at the largest dry size, $165 \mathrm{~nm}$, was utilized as the larger particles contribute to the optical properties the most (Sundström et al., 2009).

\subsection{MAX-DOAS measurements}

Multi-axis differential optical absorption spectroscopy (MAX-DOAS) is a technique to derive profiles of atmospheric gases and aerosols using spectral radiation measurements under different (mostly slant) elevation angles (Hönninger and Platt, 2002; Leser et al., 2003; Van Roozendael et al., 2003; Wittrock et al., 2004; Hönninger et al., 2004; Wagner et al., 2004; Sinreich et al., 2005; Heckel et al., 2005; Frieß et al., 2006; Irie et al., 2008).

For the retrieval of aerosol extinction profiles, usually the atmospheric absorption of the oxygen collision-induced dimer $\left(\mathrm{O}_{2}-\mathrm{O}_{2}\right.$ or $\left.\mathrm{O}_{4}\right)$ is analyzed. Since the atmospheric $\mathrm{O}_{2}$ concentration is almost constant, changes in the observed absorption can be attributed to changes in the atmospheric radiative transfer, e.g. caused by the influence of aerosol scattering and absorption (Wagner et al., 2004; Frieß et al., 2006). By comparison with a forward model which describes the effects of aerosols on the MAX-DOAS measurements, aerosol properties can be inverted from the measured $\mathrm{O}_{4}$ absorption. Usually MAX-DOAS aerosol retrieval consists of two steps: first, the $\mathrm{O}_{4}$ optical depth is retrieved from the measured spectra using the DOAS technique (Platt and Stutz, 2008). In a second step, the aerosol properties are inverted by comparing the measured $\mathrm{O}_{4}$ optical depths to those simulated by a radiative transfer model. As was shown by Frieß et al. (2006) and Clémer et al. (2010), dependent on the wavelength and atmospheric visibility, typically 1-3 independent pieces of information on the aerosol extinction profile can be obtained from MAX-DOAS $\mathrm{O}_{4}$ observations. It is noted that usually for some of the aerosol optical properties (e.g. the single scattering albedo or the asymmetry parameter) either fixed values are assumed or information from independent measurements (e.g. sun photometers or in-situ measurements) is used.

In this study MAX-DOAS aerosol retrievals from four groups are included: the Belgium Institute for Space Aeronomy (BIRA), the Institute for Environmental Physics of the University of Heidelberg (IUPHD), the Japan Agency for Marine-Earth Science and Technology, Research Institute for Global Change (JAMSTEC), and the Max-PlanckInstitute for Chemistry (MPI). All groups use similar retrieval schemes for the spectral analysis of the $\mathrm{O}_{4}$ absorption (first step); further details of the spectral analysis can be found in Roscoe et al. (2010). For the inversion of the aerosol properties by comparison with radiative transfer simulations (second step) two different approaches are used. BIRA, IUPHD, and JAMSTEC apply the optimal estimation method (Rodgers, 2000), which yields height-resolved profiles of the aerosol extinction coefficient. MPI uses a more simplified approach following the technique of $\mathrm{Li}$ et al. (2010): the aerosol extinction profile is described by only two parameters (the total aerosol optical depth and the aerosol layer height) which are determined by fitting the measured $\mathrm{O}_{4}$ optical depths to the radiative transfer simulations using a least squares method (the aerosol extinction is assumed to be constant within the aerosol layer).

The properties of the different MAX-DOAS measurements and the specific settings of the aerosol inversion schemes are summarized in Table 1 . Note that most groups analyze the $\mathrm{O}_{4}$ absorption band at $477 \mathrm{~nm}$ which is close to the wavelengths of the in-situ aerosol measurements. Because of the limited spectral range of the instrument, MPI uses the $\mathrm{O}_{4}$ band at $360 \mathrm{~nm}$. It should also be noted that some uncertainty with respect to the absolute value of the $\mathrm{O}_{4}$ absorption cross section exists (Wagner et al., 2009; Clémer et al., 2010), and all groups apply a correction factor to the retrieved $\mathrm{O}_{4}$ absorption ranging between 0.75 and 0.83 , see Table 1. Additional information on the individual retrievals 
Table 1. Overview of the main MAX-DOAS technical and inversion properties.

\begin{tabular}{|c|c|c|c|c|}
\hline & $\mathrm{BIRA}^{\mathrm{a}}$ & IUPHD $^{\mathrm{b}}$ & JAMSTEC ${ }^{\mathrm{C}}$ & $\mathrm{MPI}^{\mathrm{d}}$ \\
\hline Wavelength & $400-700 \mathrm{~nm}$ & $290-790 \mathrm{~nm}$ & $223-558 \mathrm{~nm}$ & $310-461 \mathrm{~nm}$ \\
\hline $\begin{array}{l}\text { Spectral resolution } \\
\text { (FWHM) }\end{array}$ & $0.95 \mathrm{~nm}$ & $0.5-0.6 \mathrm{~nm}$ & $0.7 \mathrm{~nm}$ & $0.5-0.9 \mathrm{~nm}$ \\
\hline Field of view & $0.8^{\circ}$ & $0.9^{\circ}$ & $<1^{\circ}$ & $1.2^{\circ}$ \\
\hline $\mathrm{O}_{4}$ bands used & $477 \mathrm{~nm}$ & $477 \mathrm{~nm}^{\mathrm{e}}$ & $477 \mathrm{~nm}^{\mathrm{f}}$ & $360 \mathrm{~nm}$ \\
\hline Scaling factor & 0.75 & 0.8 & 0.8 & 0.83 \\
\hline Elevation angles $\left({ }^{\circ}\right)$ & $1,2,4,5,8,10,15,30,90$ & $2,4,8,15,30,90$ & $2,4,8,15,30,90^{\mathrm{g}}$ & $2,4,6,8,10,15,30,90$ \\
\hline Inversion scheme & Optimal estimation & Optimal estimation & Optimal estimation & Least squares \\
\hline \multirow[t]{2}{*}{ Time resolution } & $15 \mathrm{~min}$ & $15 \mathrm{~min}$ & $30 \mathrm{~min}$ & $10 \mathrm{~min}$ \\
\hline & 1 elevation sequence & 2-3 elevation sequences & 1 elevation sequence & 1 elevation sequence \\
\hline Radiative transfer model & LIDORT v3. $3^{\mathrm{h}}$ & SCIATRAN $^{\mathrm{i}}$ & MCARaTS ${ }^{j}$ & McARTim $^{\mathrm{k}}$ \\
\hline Aerosol optical properties & AERONET $^{1}$, in-situ & $\mathrm{OPAC}^{\mathrm{m}}$ & $\omega_{0}: 0.95$, AP: $0.65^{\mathrm{n}}$ & $\omega_{0}: 0.95$, AP: 0.68 \\
\hline Time period used & 19.6.-21.7. & 23.6.-26.9. & 19.6.-24.7. & 22.6.-14.7. \\
\hline Vertical discretization & $200 \mathrm{~m}$ & $200 \mathrm{~m}$ & $1 \mathrm{~km}$ & $20-5000 \mathrm{~m}$ \\
\hline
\end{tabular}

${ }^{a}$ Clémer et al. (2010); ${ }^{b}$ Frieß et al. (2006); ${ }^{\mathrm{c}}$ Irie et al. (2008, 2009); ${ }^{\mathrm{d}} \mathrm{Li}$ et al. (2010); Wagner et al. (2011); ${ }^{\mathrm{e}} \sigma_{\mathrm{ep}}$ is retrieved at $450 \mathrm{~nm}$ due to specifications of the radiative transfer model and the employed OPAC database (Hess et al., 1998); ${ }^{\mathrm{f}}$ The retrieved $\sigma_{\mathrm{ep}}$ is for $476 \mathrm{~nm}$, which is the $\mathrm{O}_{4}$ cross-section-weighted mean wavelength over the fitting window used. ${ }^{\mathrm{g}}$ from 08.06.-21.06. $3^{\circ}$ was used instead of $2^{\circ} ;{ }^{\mathrm{h}}$ Spurr (2008); ${ }^{\mathrm{i}}$ Rozanov et al. (2001); ${ }^{\mathrm{j}}$ Iwabuchi (2006); ${ }^{\mathrm{k}}$ Deutschmann and Wagner (2008); ${ }^{\mathrm{l}}$ Holben et al. (1998); ${ }^{\mathrm{m}}$ Calculated for an assumed mixture of water soluble and soot particles with a number mixing ratio of 0.46 and 0.54 , respectively (Hess et al., 1998 ); ${ }^{\mathrm{n}} \omega_{0}$ : single scattering albedo, AP: asymmetry parameter;

can be found in a comparison exercise of the spectral analyses during the CINDI campaign (Roscoe et al., 2010) and in a MAX-DOAS aerosol comparison paper by Frieß et al. (2011).

\subsection{Lidar measurements}

The LIDAR CAELI (CESAR Water Vapour, Aerosol and Cloud Lidar; Apituley et al., 2009) is a high-performance, multi-wavelength Raman LIDAR, capable of providing round-the-clock measurements. The instrument is part of the European Aerosol Research Lidar Network (EARLINET), and provides profiles of volume backscatter and extinction coefficients of aerosol particles, the depolarization ratio, and water-vapor-to-dry-air mixing ratio. A high-power Nd:YAG laser transmits pulses at 355, 532, and $1064 \mathrm{~nm}$. Because a large telescope is essentially blind for LIDAR signals from close to the instrument, a second, small telescope is needed to cover the near range, in particular for measurements in the planetary boundary layer. The LIDAR echoes at the elastic and Raman scattered wavelengths are relayed to the photo detectors through optical fibers. The LIDAR returned signals strongly depend on the range $h$ and decrease with $h^{2}$. Multiplication with $h^{2}$ thus removes the range dependence. In this way, the range-corrected signals for the vertically pointing ground-based LIDAR are obtained. Range-corrected signals at $1064 \mathrm{~nm}$ are dominated by particle backscatter and are therefore well-suited to display aerosol layering structure and dynamics and to detect the presence of clouds (see e.g. Fig. 7a).
Raman LIDAR instruments can retrieve aerosol extinction profiles using a single LIDAR signal at a nitrogen Raman scattered wavelength (here: $387 \mathrm{~nm}$ ), with just the help of an atmospheric density profile (e.g. a radio sonde or an atmospheric model) (Ansmann et al., 1992). However, two major problems occur when extinction needs to be calculated at daytime and close to the ground:

1. Raman signals are relatively weak and often dominated by the daylight background, and

2. the geometry of the LIDAR instrument, the so-called overlap-function, dictates a minimum distance beyond which unbiased extinction values can be derived.

For CAELI, the Raman signals at $387 \mathrm{~nm}$ are strong enough for daytime performance up to a few $\mathrm{km}$ altitude, however, trustworthy extinction profiles start between 500 and $1000 \mathrm{~m}$ above ground.

To work around the overlap problem for this study, extinction profiles were calculated via the Raman aerosol backscatter profiles down to about $60 \mathrm{~m}$ above ground. This was achieved by calculating the Raman aerosol backscatter profile from the ratio of the $\mathrm{N}_{2}$ Raman signal and the elastic (normal) LIDAR signal (Ansmann et al., 1992). Because both of these signals are affected in the same way by the overlap function, for a well-aligned LIDAR system, it does not affect their ratio. For CAELI, correct alignment could be verified using methods described by Freudenthaler (2008). 
For a given measurement, the Raman backscatter $(\beta)$ and extinction $\left(\sigma_{\mathrm{ep}}\right)$ profiles are calculated. From these profiles the LIDAR ratio LR is determined:

$\operatorname{LR}(h)=\frac{\sigma_{\mathrm{ep}}(h)}{\beta(h)}$

where $h$ denotes the height above the ground.

The LIDAR ratio is only valid beyond the minimum overlap height where both $\sigma_{\mathrm{ep}}$ and $\beta$ are valid. However, it can be argued that within well-mixed states of the boundary layer, LR should be fairly constant, since it is representative for a particular type of aerosol and only RH can be a significant factor determining the LR (Salemink et al., 1984; Ackermann, 1998). So by assuming an effective $L R, L^{\prime}$, the backscatter profile at lower altitudes can be converted to an extinction profile using $\mathrm{LR}^{\prime}$ as a conversion factor in Eq. (7). By varying $L^{\prime}$ over a range of values and comparing to insitu measurements, it can be determined whether the values obtained in this way are consistent.

\section{Results}

The results of the in-situ measurements are presented in the first Sects. 4.1 to 4.3. First, the results of the WetNeph analysis and the factors influencing $f(\mathrm{RH})$ at Cabauw are discussed in Sects. 4.1 and 4.2. A closure study using different aerosol in-situ measurements is shown in Sect. 4.3. The prediction of $f(\mathrm{RH})$ without explicit WetNeph measurements at Cabauw is also discussed in Sect. 4.3. The ambient aerosol extinction coefficient is compared to MAX-DOAS and LIDAR measurements in Sect. 4.4.

\subsection{WetNeph analysis}

During the four-month campaign the WetNeph and DryNeph were running continuously without any major interruptions (except for a 70-h break at the end of August). The WetNeph was set up to measure humidograms for most of the time, except for two 7- and 11-day long periods in July and August, where the relative humidity was set on a constant value of approximately $82-85 \%$. This was done to further investigate diurnal cycles. Due to the large variation of air masses, no explicit diurnal cycles were found. The humidograms were parameterized with an empirical equation, which has been used in previous studies (Clarke et al., 2002; Carrico et al., 2003) and has been found to best describe the individual branches (hydration, dehydration separately):

$$
f(\mathrm{RH})=a(1-\mathrm{RH})^{-\gamma},
$$

where $a$ and $\gamma$ are two independent curve fit parameters ( $a$ is the intercept at $\mathrm{RH}=0 \%$ and $\gamma$ parameterizes the magnitude of the scattering enhancement). The humidograms were averaged (3-h mean values for $2 \%$ wide RH-bins) and fitted with Eq. (8) for $\mathrm{RH}>70 \%$. No differences were found at these high RH values between the hydration and dehydration branch). During the periods when the WetNeph was operated in a constant RH mode Eq. (8) was used with a campaign mean value for $a=0.7$ (upper branch only).

Figure 1a shows the temporal evolution of $f(\mathrm{RH})$ for $\mathrm{RH}=85 \%$ for the entire campaign period. The values varied between mid June and the beginning of October between approximately 1.3 and 3.9 (10th percentile $=1.93$, 90th percentile $=2.9$ ). The corresponding measured dry and wet (at $\mathrm{RH}=85 \%$ ) scattering coefficients (at $550 \mathrm{~nm}$ ) and dry absorption coefficients (at $637 \mathrm{~nm}$ ) are shown in Fig. 1b. The main contribution to the ambient extinction coefficient (= scattering plus absorption coefficient) is the scattering coefficient, since the absorption coefficient is about an order of magnitude lower than the scattering coefficient.

The distinct periods of lowered and elevated $f(\mathrm{RH})$ values (see Fig. 1a) were correlated with the origin of the air masses as revealed from 48-h air-mass back trajectories which were calculated using the FLEXTRA trajectory model (Stohl et al., 1995; Stohl and Seibert, 1998) and ECMWF (European Centre for Medium Range Weather Forecasts) meteorological data (trajectories are provided by NILU at www.nilu. no/trajectories). The result is shown in Fig. 2a where the back trajectories are color coded by the $f(\mathrm{RH}=85 \%)$ measured at Cabauw. In general, the $f(\mathrm{RH}=85 \%)$ is lower in air masses originating from the continent and urban regions (like Rotterdam or Ruhr area), probably reflecting the presence of aerosol particles with lower hygroscopicity resulting from anthropogenic emissions and lower sea salt content. Air masses that were transported over the North Atlantic Ocean or the North Sea prior to their arrival in Cabauw likely contain more sea-salt leading to higher hygroscopic growth and therefore to higher values of $f(\mathrm{RH}=85 \%)$. Mixtures of both extremes are frequently observed, for example air parcels that have their origin over the Atlantic Ocean and are passing over heavy industrialized areas (like the Rotterdam area or southern Great Britain) where the addition of anthropogenic pollution leads to lower hygroscopicity.

Examples of typical humidograms measured at Cabauw are shown in Fig. 2b-f. These averaged humidograms are sorted according to the origin of the air masses arriving at the site. A typical maritime case is presented in Fig. 2b (selection criteria used: direction of arriving air parcel between $45^{\circ}<\theta<315^{\circ}, f(\mathrm{RH}=85 \%, 550 \mathrm{~nm})>3.5$, average of $4 \mathrm{hu}-$ midograms). This humidogram shows a sudden increase of $f(\mathrm{RH})$ at $\sim 65 \% \mathrm{RH}$ (deliquescence) during the hydration mode (increase of RH, dark blue circles). During the dehydration mode (humidifier constantly at high RH and dryer on, light blue circles), the deliquescence RH is passed and $f(\mathrm{RH})$ decreases until $\mathrm{RH}=\sim 58 \%$. This is not the crystallization $\mathrm{RH}$, which unfortunately can not be measured with our set-up, due to temperature and flow conditions inside the WetNeph (see Sect. 3.1.2). The distinct hysteresis behavior indicates that an almost pure maritime aerosol consisting mainly of inorganic salts - e.g. $\mathrm{NaCl}-$ was detected 
(a)

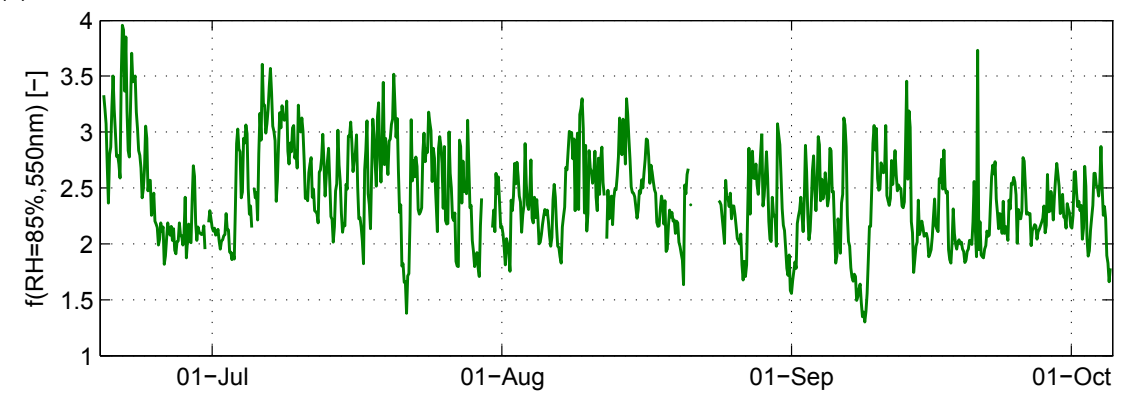

(b)

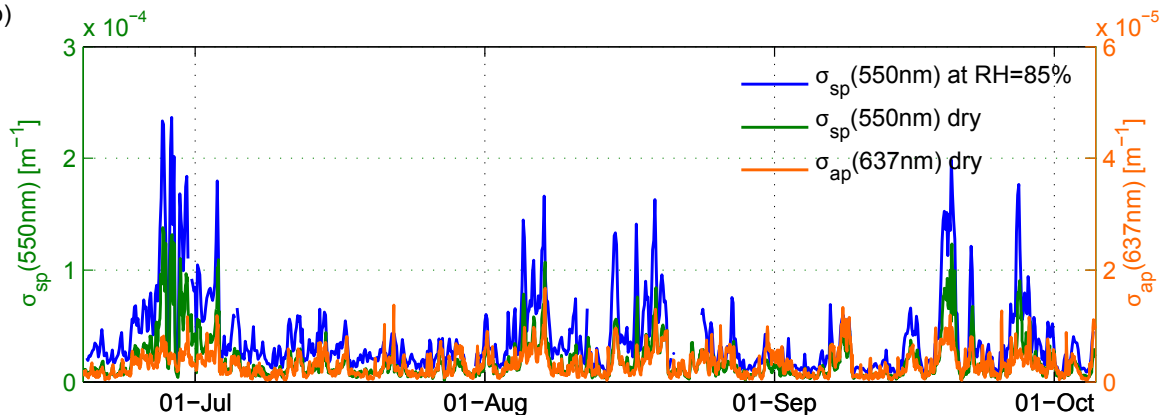

Fig. 1. Panel (a) Time series of the scattering enhancement factor $f(\mathrm{RH}=85 \%, 550 \mathrm{~nm})$ measured at Cabauw, The Netherlands, over the period from mid June to the beginning of October 2009. Panel (b) Scattering coefficient at $\lambda=550 \mathrm{~nm}$ at $\mathrm{RH}=85 \%$ (blue line) and at dry conditions (green line) measured by the humidified nephelometer (WetNeph) and reference nephelometer (DryNeph). The absorption coefficient at $\lambda=637 \mathrm{~nm}$ (orange line) was measured by the multi-angle absorption photometer (MAAP) at dry conditions.

here. Figure $2 \mathrm{~d}$ and e are two further examples of air masses having a maritime origin, although they show no clear deliquescence behavior. The maritime slightly polluted case (Fig. 2d; with $225^{\circ}<\theta<315^{\circ}$ and $f(\mathrm{RH}=85 \%, 550 \mathrm{~nm})$ $>3$, average of 31 humidograms) reveals a similarly high magnitude of $f(\mathrm{RH})$ as the clean maritime case (Fig. 2b), but without deliquescence, while the maritime heavily polluted case is characterized by much lower values of $f(\mathrm{RH})$ (Fig. 2e; with $225^{\circ}<\theta<315^{\circ}$ and $f(\mathrm{RH}=85 \%, 550 \mathrm{~nm})<2$, average of 25 humidograms). This is probably caused by additional pollution and/or a higher fraction of organics, which suppresses the deliquescence and/or reduces the hygroscopic growth of the particles (Ming and Russell, 2001). Figure $2 \mathrm{c}$ and $\mathrm{f}$ show two examples of air masses having a continental origin (continental south: $135^{\circ}<\theta<225^{\circ}$ and $f(\mathrm{RH}=85 \%, 550 \mathrm{~nm})<2$, average of 48 humidograms; continental east: $60^{\circ}<\theta<135^{\circ}$, average of 75 humidograms). Both humidograms show a smooth increase of $f(\mathrm{RH})$ without a distinct deliquescence behavior. This means that the particles are liquid over a broad RH range. The continental south air masses (Fig. 2c) show the lowest values of $f(\mathrm{RH})$ of $\sim 1.9$ at $\mathrm{RH}=85 \%$. These air parcels originated from northern France, Belgium and The Netherlands south of Cabauw. It is emphasized that these are examples of selected air masses only. A simple and generalized categorization using the air mass trajectories could not be established due to the high variability of size and composition and the short measurement period. For a better statistical analysis a longer time period of at least a year would be desirable.

\subsection{Factors influencing $f(\mathrm{RH})$ at Cabauw}

What determines the magnitude of $f(\mathrm{RH})$ and what other parameters can be used as proxies to estimate $f(\mathrm{RH})$ ? To answer these questions, the main in-situ aerosol parameters available during our measurement period were crosscorrelated. The result is presented in Fig. 3, which shows the coefficient of determination $R^{2}$ (squared correlation coefficient) of $f(\mathrm{RH}=85 \%)$ versus each parameter (the positive or negative sign shows the algebraic sign of the correlation coefficient). The strongest correlation $\left(R^{2}=0.72\right)$ of $f(\mathrm{RH}=85 \%)$ exists with the hygroscopic growth factor $g(\mathrm{RH}, 165 \mathrm{~nm})$ measured by the H-TDMA for the dry diameter of $165 \mathrm{~nm}$. The chemical composition of the particle at this rather large diameter is the main factor that determines its ability to grow. This value seems to be the best proxy measured independently that can be used to estimate $f(\mathrm{RH})$. It will be shown later that together with the measured size distribution and Mie theory this factor can be used to get an estimate of $f(\mathrm{RH})$.

The BC volume fraction $V_{\mathrm{BC}} / V_{\text {tot }}$ (assuming a density of $2.1 \mathrm{gcm}^{-3}$ ) shows only a weak (negative) correlation with $f(\mathrm{RH})$. Also the coarse mode volume fraction $V_{\mathrm{APS}} / V_{\text {tot }}$ is 

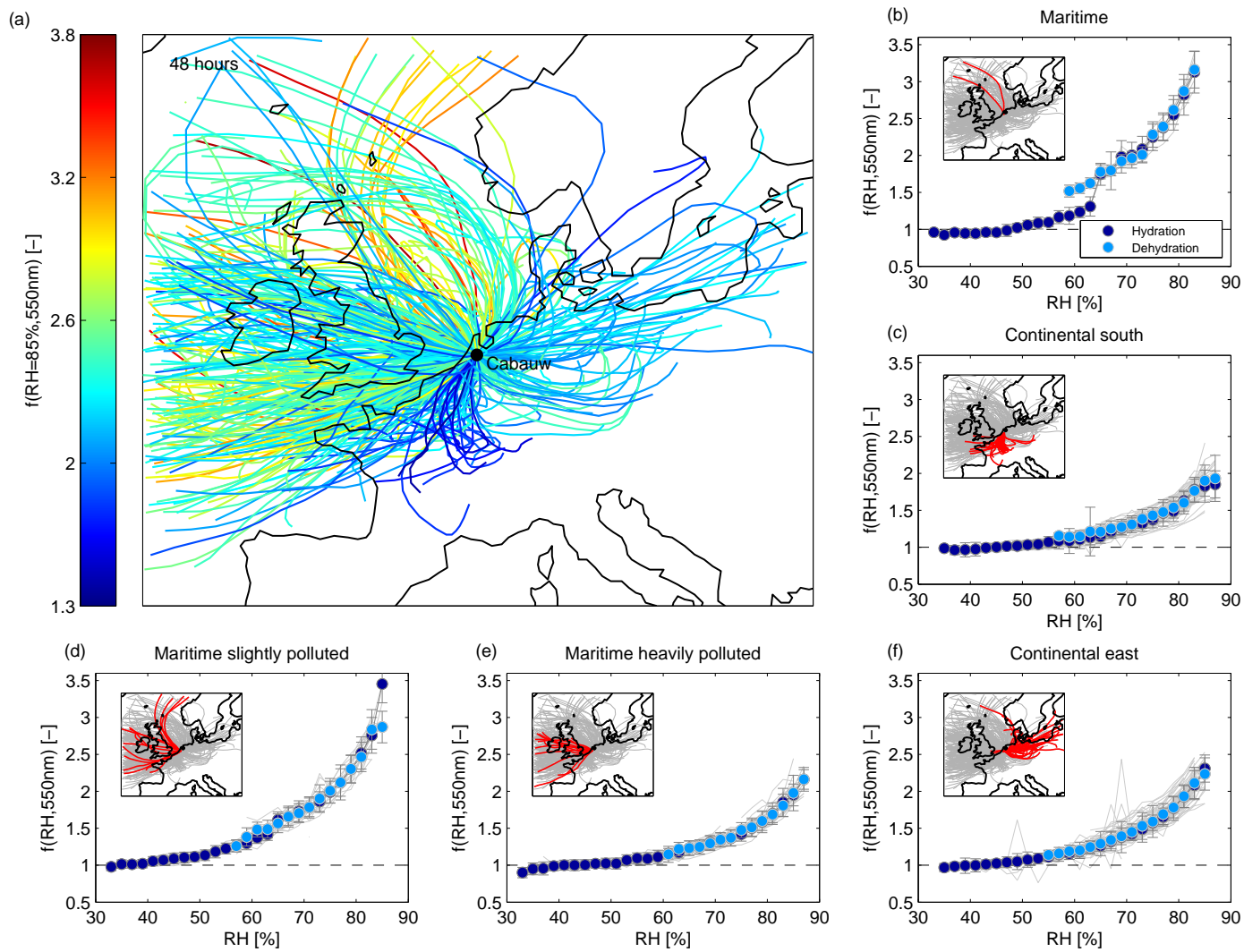

Fig. 2. Panel (a) FLEXTRA trajectories ( $48 \mathrm{~h}$ backward calculation) of air parcels arriving at Cabauw. The trajectories are color coded with the mean aerosol scattering enhancement $f(\mathrm{RH}=85 \%, 550 \mathrm{~nm})$ measured at the site. Panels (b)-(f) Example humidograms classified by the origin of the air masses. Dark blue circles denote averages of $f(\mathrm{RH})$ for the hydration branch of the humidogram, while light blue circles are averages of the dehydration branch (2\% RH bins). Underlined in grey are the individual humidograms of each trajectory. Error bars denote the standard deviation.

only weakly (positively) correlated to $f(\mathrm{RH})$. These rather low correlations to $f(\mathrm{RH})$ are accompanied by significant correlations of both $V_{\mathrm{BC}} / V_{\text {tot }}$ and $V_{\mathrm{APS}} / V_{\text {tot }}$ to $g(\mathrm{RH})$. The positive correlation can be explained by the fact that a larger coarse mode volume fraction is an indicator for the presence of sea salt, which exhibits a higher hygroscopic growth (therefore positively correlated). Increased BC fractions on the other hand are an indicator for anthropogenic pollution with a reduced hygroscopic growth, causing a negative correlation because high amounts of $\mathrm{BC}$ in the aerosol reduce its ability for hygroscopic growth (Weingartner et al., 1997).

The mean diameter $D_{\text {mean }}=N^{-1} \int_{0}^{\infty}\left(D_{\text {dry }}\right.$ $\left.\mathrm{d} N / \operatorname{d} \log D_{\text {dry }}\right) \operatorname{dlog} D_{\text {dry }}$ measured by the APS (representative for the coarse mode) and by the SMPS and APS (representative for the entire size distribution) show similar values of $R^{2}$ as the coarse mode fraction if compared to $f(\mathrm{RH})$. Both coarse mode proxies $\left(V_{\mathrm{APS}} / V_{\text {tot }}\right.$ and $\left.D_{\mathrm{APS}}\right)$ are more highly correlated to $g(\mathrm{RH})$ than to $f(\mathrm{RH})$, because $f(\mathrm{RH})$ is a measure for the entire size distribution (where the hygroscopic properties may change with size) while $g(\mathrm{RH})$ is representative for only one dry diameter. This may also point towards effects of non-linearity in the Mie- scattering, where both size and chemical composition are input parameters. If the chemical composition (hygroscopic growth and refractive index) is assumed to be constant for a given wavelength, $f(\mathrm{RH})$ will decrease with increasing particle size. This can be compensated if the size changes concurrently with its hygroscopicity. A similar effect was e.g. observed and modeled for Arctic aerosol (see Fig. 9 in Zieger et al. 2010), where smaller but less hygroscopic particles had a similar magnitude of $f(\mathrm{RH})$ compared to larger but more hygroscopic particles (in that case the coarse mode was also dominated by hygroscopic sea salt).

The scattering Ångström exponent $\alpha_{\mathrm{sp}}$ (retrieved similar to Eq. (5) but using $\sigma_{\mathrm{sp}}$ instead of $\sigma_{\mathrm{ap}}$ ) of the dry and wet (at $\mathrm{RH}=85 \%$ ) scattering coefficient show no correlation with $f(\mathrm{RH}) . \alpha_{\mathrm{sp}}$ is commonly used as a proxy for the mean size (as can be seen in the clear anticorrelation between $\alpha_{\mathrm{sp}}$ and the coarse mode volume fraction $V_{\mathrm{APS}} / V_{\text {tot }}$ ). This implies that they can not be used as a simple proxy for $f(\mathrm{RH})$, as for example it has been proposed and verified for the typical aerosol found at the high alpine site Jungfraujoch (JFJ) (Nessler et al., 2005a; Fierz-Schmidhauser et al., 2010a). The reason for this is the occasional presence of 


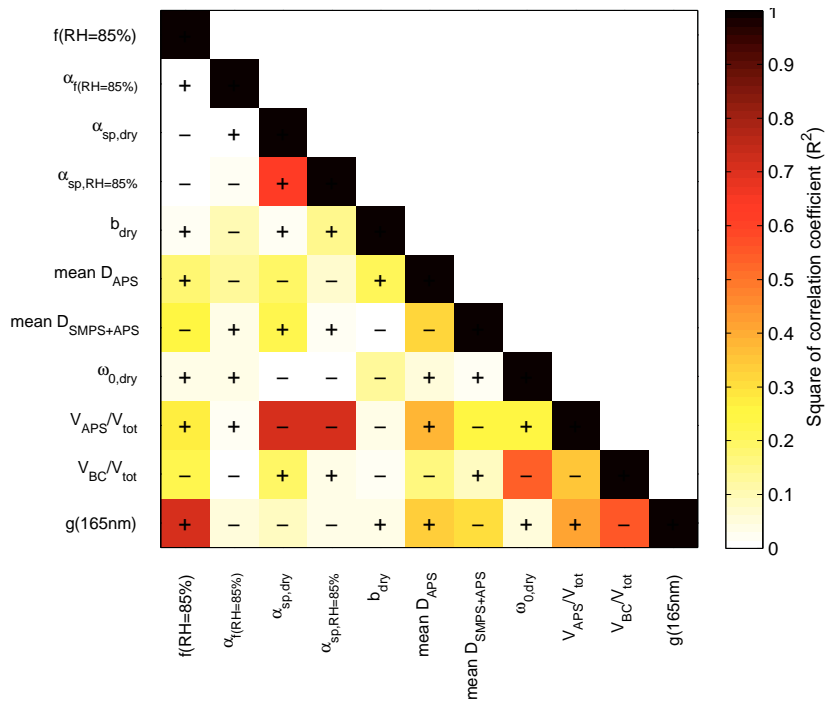

Fig. 3. Correlation plot of all intensive aerosol parameters measured in-situ at the Cabauw tower. $f(\mathrm{RH}=85 \%, 550 \mathrm{~nm})$ : scattering enhancement factor; $\alpha_{\mathrm{f}(\mathrm{RH})}$ : Ångström exponent of $f(\mathrm{RH}=85 \%$, $550 \mathrm{~nm}) ; \alpha_{\mathrm{sp}, \text { dry }}$ : Ångström exponent of scattering coefficient at

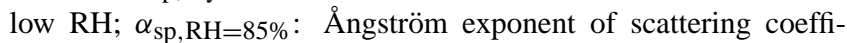
cient at $\mathrm{RH}=85 \% ; b_{\text {dry }}$ : backscatter fraction (at $\lambda=550 \mathrm{~nm}$ ) at low RH; $D_{\text {APS }}$ : mean (dry) diameter of APS size distribution measurement; $D_{\text {SMPS }}$ : mean (dry) diameter of SMPS size distribution measurement; $\omega_{0 \text {, dry }}$ : single scattering albedo at low RH (at $\lambda=550 \mathrm{~nm}$ ); $V_{\mathrm{APS}} / V_{\text {tot }}$ : coarse mode fraction measured by APS and SMPS; $V_{\mathrm{BC}} / V_{\text {tot }}$ : black carbon volume fraction measured by MAAP, SMPS, and APS; $g(\mathrm{RH}=90 \%, 165 \mathrm{~nm})$ : hygroscopic growth factor measured at the dry diameter $d_{0}=165 \mathrm{~nm}$ and at $\mathrm{RH}=90 \%$ by the H-TDMA. Plus and minus signs indicate the slope of the regression line.

a hygroscopic coarse mode (sea salt) at Cabauw (and most probably for all measurement sites with maritime influence), whereas at the JFJ a coarse mode is mainly composed of mineral dust with very low hygroscopicity. Neither the dry backscattering coefficient $b_{\text {dry }}$ (measured by the nephelometer) nor the dry single scattering albedo $\omega_{0 \text {,dry }}$ (e.g. measured by the nephelometer, the MAAP and/or the aethalometer) are suitable proxies. The Ångström exponent of the scattering enhancement factor $\alpha_{f(\mathrm{RH})}$ shows no significant correlation to any in-situ parameters.

\subsection{Closure study}

To check for consistency within the aerosol in-situ measurements a closure study using Mie theory was performed. The main goal was to reproduce the WetNeph measurements using independent measurements of the hygroscopic growth factor (H-TDMA), the aerosol size distribution (SMPS and APS), the aerosol absorption (MAAP and aethalometer), and scattering properties (DryNeph). The Mie-based model is described in detail in Zieger et al. (2010). The focus was

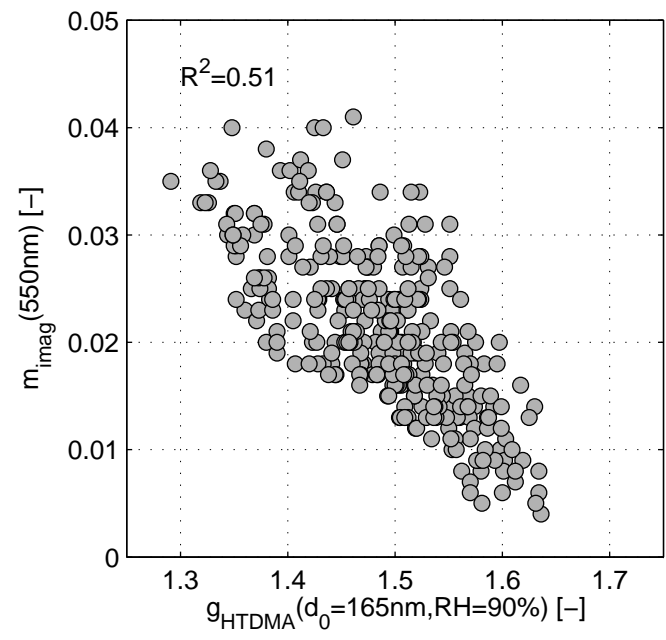

Fig. 4. Retrieved imaginary part of the complex refractive index versus the hygroscopic growth factor measured by the H-TDMA (at $d_{0}=165 \mathrm{~nm}$ and $\mathrm{RH}=90 \%$ ).

set on the period 4 July to 18 July 2009 , because during this period all instruments were operating successfully (for the other periods the SMPS did not measure). Independent measurements of the chemical composition were not available for this study, but are needed to calculate the complex refractive index used in the Mie calculations. Therefore, an inversion of the dry scattering and absorption coefficients using the measured size distribution and Mie theory was done (assuming a $50 \times 50$ field of real and imaginary parts of the refractive index). With this inversion only a mean refractive index (representative for the entire aerosol size distribution) can be derived. This procedure is not a critical issue for the WetNeph closure itself because the closure will be done for a high RH (here, at $85 \%$ ) as an example, where the particle's refractive index will be close to that of water.

The retrieval of the refractive index showed additionally that the imaginary part anticorrelates well with the hygroscopic growth factor which is measured independently by the H-TDMA $\left(R^{2}=0.51\right.$, see Fig. 4$)$. This shows that less hygroscopic particles at Cabauw are also characterized by an enhanced absorption, which indicates the presence of black carbon. A functional description (e.g. polynomial fit) can not be established due to the clear and strong presence of organic matter at Cabauw (Morgan et al., 2010), which is expected to lower the hygroscopic growth while having a minor influence on the refractive index (negligible imaginary part of the refractive index compared to BC, Nessler et al. 2005a). Therefore, an extrapolation to $g=1$ in order to estimate the imaginary part of $\mathrm{BC}$ can not be made without assumptions. The imaginary part versus the $\mathrm{BC}$ volume fraction showed a very good correlation $\left(R^{2}=0.96, m_{i}=0.68 V_{\mathrm{BC}} / V_{\mathrm{tot}}-0.0013\right.$ at $550 \mathrm{~nm})$; an extrapolation to $V_{\mathrm{BC}} / V_{\mathrm{tot}} \rightarrow 1$ would lead to an imaginary part of pure $\mathrm{BC}$ of $\sim 0.7$, which is in accordance with literature values (see e.g. Bond and Bergstrom, 


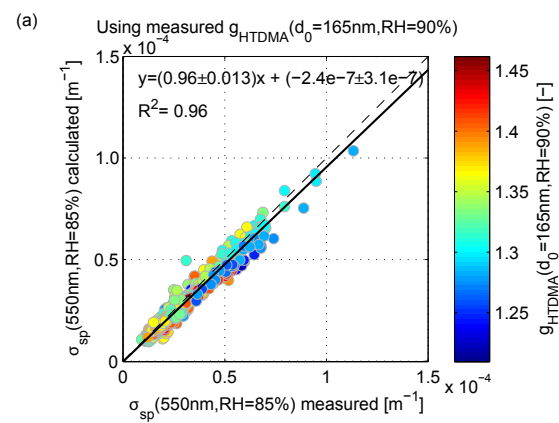

(c)

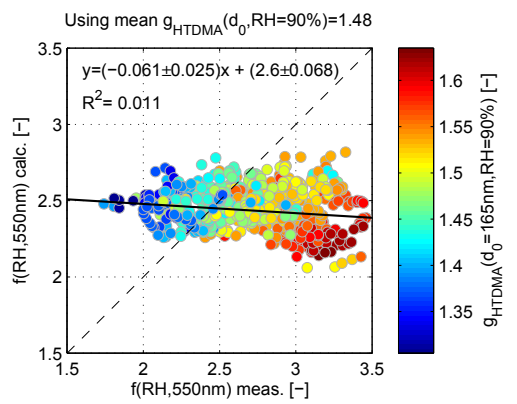

(b)

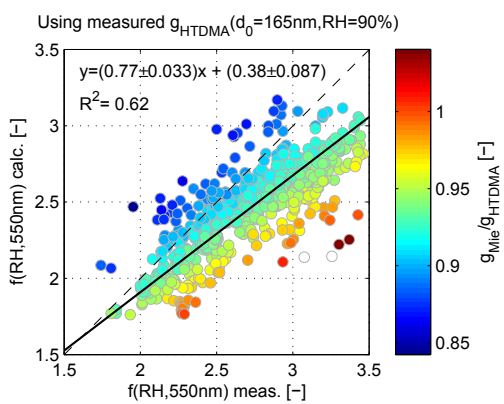

(d)

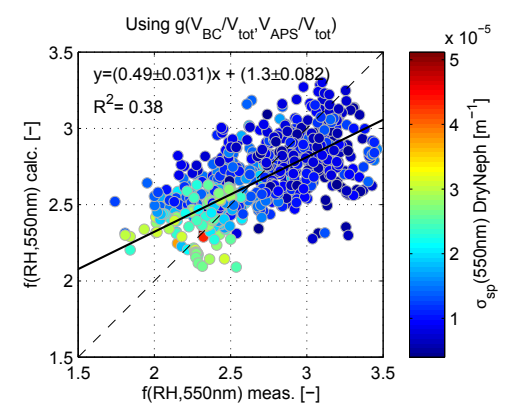

Fig. 5. Panel (a) Scattering coefficient $\sigma_{\mathrm{sp}}$ calculated vs. measured using the hygroscopic growth factor measured by the H-TDMA. Panel (b)(d) Scattering enhancement factor $f(\mathrm{RH}=85 \%, 550 \mathrm{~nm})$ calculated vs. measured values. Panel (b) The measured hygroscopic growth factor of the H-TDMA (dry diameter $d_{0}=165 \mathrm{~nm}$ ) has been used for the calculation, the color code denotes the ratio of $g_{\text {Mie }} / g_{\text {HTDMA }}$. Panel (c) A fixed value of $g\left(\mathrm{~d}_{0} \mathrm{RH}=90 \%\right)=1.48$ (mean for that period) has been used for the calculation. Panel (d) An empirical relation of $g\left(V_{\mathrm{BC}} / V_{\mathrm{tot}}, V_{\mathrm{APS}} / V_{\mathrm{tot}}\right)$ has been used for the calculation of $f(\mathrm{RH})$. All values are shown at $\mathrm{RH}=85 \%$. The solid black line represents a bivariate linear regression including weights (with calculated uncertainty of slope and intercept). The 1:1-line is shown as a dashed line.

2006). The good correlation is not surprising since the imaginary part was retrieved using the $\mathrm{BC}$ measurements from the MAAP in conjunction with the size distribution and nephelometer measurements.

The hygroscopic growth factor $g(\mathrm{RH})$ is measured by the H-TDMA at the dry diameters of $35,50,75,110$, and $165 \mathrm{~nm}$. Since the H-TDMA measured at a constant $\mathrm{RH}=90 \%$, the value of $g(\mathrm{RH})$ for different $\mathrm{RH}$ was calculated using Eq. (2), where instead of the water activity $a_{w}$ the relative humidity RH is used. The largest diameter is the most important one for the determination of the optical properties. The change of the size distribution at $\mathrm{RH}=85 \%$ was calculated assuming that particles larger than $165 \mathrm{~nm}$ have the same hygroscopic growth as the 165-nm-particles. The result for the wet scattering coefficient $\sigma_{\mathrm{sp}}(\mathrm{RH}=85 \%)$ is presented in Fig. 5a (the results are shown for $\lambda=550 \mathrm{~nm}$ and are similar for the other nephelometer wavelengths). For the linear regression a bivariate weighted fit according to York et al. (2004) as described in Cantrell (2008) with the assumption of a $10 \%$ error in the measured (Anderson et al., 1996) and calculated scattering coefficients has been used. This method includes the uncertainties of both the $x$ and $y$ variables and allows the calculation of the uncertainties of the retrieved slope and intercept. The high correlation coefficient and the good linear relationship are clear indicators that the aerosol in-situ measurements are consistent with each other (at least for the investigated period). The slightly lower values of the calculated $\sigma_{\mathrm{sp}}(\mathrm{RH}=85 \%)$ can be explained by the fact that the H-TDMA measures only rather small particles and misses the coarse mode which might include large hygroscopic particles such as sea salt. This is also seen in the applied color code. While the H-TDMA measures particles with low hygroscopicity (e.g. $g<1.3$, blue points) the measured values of $\sigma_{\mathrm{sp}}(\mathrm{RH}=85 \%)$ are larger than the calculated ones. One reason could be the presence of a mixture containing a polluted fine mode (e.g. soot) and a coarse mode consisting of sea salt, which can not be measured with the H-TDMA. The calculated $f(\mathrm{RH}=85 \%)$ using the measured $g(\mathrm{RH})$ of the H-TDMA is therefore lower than that derived from the measurements (see Fig. 5b).

Keeping the dry refractive index at a fixed value does not significantly change the agreement within this closure study. Despite the fact that the number size distribution dominates the magnitude of the calculated dry scattering coefficient the variation of the dry refractive index still has an influence. Taking e.g. $m=1.5291+0.024 i$ at $550 \mathrm{~nm}$ (used in Fierz-Schmidhauser et al. (2010b) for polluted air at Mace Head, Ireland) gives $y=(1.0 \pm 0.014) x+(2.2 \times$ 


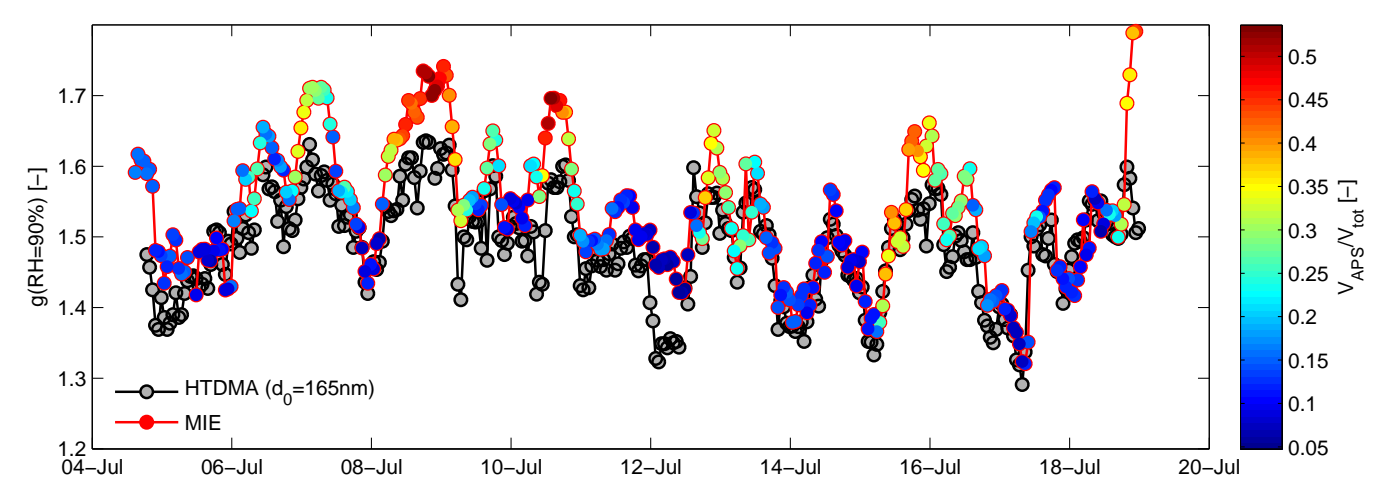

Fig. 6. Time series of the hygroscopic growth factor measured by the H-TDMA (black line) and retrieved from WetNeph, DryNeph, SMPS, APS measurements and Mie theory (red line). The color code denotes the coarse mode volume fraction measured by the APS and SMPS.

$\left.10^{-7} \pm 2.4 \times 10^{-7}\right) \mathrm{m}^{-1}$ and $R^{2}=0.94$ for the comparison of the wet scattering coefficients to the calculated values (analog to Fig. 5a). For the comparison of the measured and calculated $f(\mathrm{RH})$ using the growth factor of the $\mathrm{H}$ TDMA (analog to Fig. 5b) gives a slightly lower agreement $y=(0.64 \pm 0.029) x+(0.57 \pm 0.078)$ and $R^{2}=0.61$.

To further demonstrate the effect of the limited size range of the H-TDMA measurements for the closure study, the hygroscopic growth factor was derived via Mie theory from the WetNeph, DryNeph and size distribution measurements (for more details see Zieger et al. 2010). The results are presented in Fig. 6 together with the hygroscopic growth factors measured with the H-TDMA (both at $\mathrm{RH}=90 \%$ ). While the correlation between both methods is quite good $\left(R^{2}=0.71\right)$ and the agreement is good for certain periods, the WetNeph based $g_{\text {Mie }}(\mathrm{RH})$ is generally slightly higher $\left(g_{\text {Mie }}(\mathrm{RH})=1.3 g_{\text {HTDMA }}(\mathrm{RH})-0.4\right.$ derived by an orthogonal linear regression), but there are certain periods where the differences increase substantially. These are most probably episodes with enhanced sea salt influence, as can be seen by an enlarged coarse mode measured by the APS and SMPS (see color code in Fig. 6).

The calculations were repeated using a fixed hygroscopic growth factor of $g\left(\mathrm{~d}_{0}, \mathrm{RH}=90 \%\right)=1.48$ (mean campaign value for $165 \mathrm{~nm}$ ) to demonstrate the effect of assuming a constant hygroscopic growth. The result is depicted in Fig. 5c. The calculated $f(\mathrm{RH})$ values are clearly lower than the measured values of $f(\mathrm{RH})$. The color code shows the $g(\mathrm{RH})$ measured by the H-TDMA, which is high for the underestimated and low for the overestimated values of $f(\mathrm{RH})$.

If $f(\mathrm{RH})$ needs to be predicted, the chemical composition (especially the coarse mode composition) needs to be known. Fierz-Schmidhauser et al. (2010a) and Nessler et al. (2005a) used one mean growth factor to successfully predict $f(\mathrm{RH})$ at the JFJ, but they were in a comfortable position that the aerosol coarse mode consisted only of non-hygroscopic mineral dust.
The question arises whether other continuously measured aerosol properties can be used as a proxy to estimate $f(\mathrm{RH})$ or $g(\mathrm{RH}) . f(\mathrm{RH})$ correlates poorly with other in-situ measured parameters as already shown in Fig. 3, but clearly correlates with $g(\mathrm{RH}) . g(\mathrm{RH})$ on the other hand correlates well with the coarse mode and black carbon volume fraction. An empirical equation was retrieved from the available measurements

$$
\begin{aligned}
g(\mathrm{RH}=85 \%)= & b_{1}+b_{2} V_{\mathrm{BC}} / V_{\mathrm{tot}}+b_{3} V_{\mathrm{APS}} / V_{\mathrm{tot}}+ \\
& b_{4} V_{\mathrm{APS}} / V_{\mathrm{tot}} \cdot V_{\mathrm{BC}} / V_{\mathrm{tot}}
\end{aligned}
$$

with $b_{1}=1.38, b_{2}=-1.64, b_{3}=0.35$, and $b_{4}=-1.77$ and found to be the best suitable equation. The result of the $f(\mathrm{RH})$ calculation using Eq. 9 for $g(\mathrm{RH})$ compared to the measurements is presented in Fig. 5d. Although the variation is quite large, an improvement compared to the constant chemistry assumption is clearly seen. Nevertheless, these examples demonstrate the need for a full chemical analysis and measured size distribution to predict $f(\mathrm{RH})$ if no humidified nephelometer (or at least H-TDMA) measurements are available.

\subsection{Comparison to remote sensing data}

The WetNeph measurements allow the determination of the ambient extinction coefficient, assuming that the absorption coefficient does not change with RH. This assumption can be made, because the scattering is the dominant part of the extinction (median $\omega_{0}=0.81,10$ th percentile $\omega_{0}=0.70$, 90th percentile $\omega_{0}=0.89$ at dry conditions for the entire campaign) and model studies for free tropospheric aerosol (although with a higher $\omega_{0}$ ) show that the effect of RH on the absorption coefficient (with respect to the extinction) is negligible (Nessler et al., 2005b). The extinction is then calculated as follows:

$\sigma_{\mathrm{ep}}(\mathrm{RH})=c_{p}\left(f(\mathrm{RH}) \sigma_{\mathrm{sp}}+\sigma_{\mathrm{ap}}\right)$. 
$\sigma_{\mathrm{sp}}$ and $\sigma_{\mathrm{ap}}$ are measured by the DryNeph and the MAAP and aethalometer under dry conditions. $c_{p}$ is a correction factor for pressure and temperature differences (see below). All optical measurements were inter- or extrapolated to the relevant wavelength using the Ångström law (Eq. (5), with $\left.\sigma_{\mathrm{ep}}\right) . \alpha_{\mathrm{ap}}=0.84$ was assumed for periods without aethalometer measurements which represents the mean value measured until the 6th of July by the aethalometer at the site. The assumption of a constant value of $\alpha_{\text {ap }}$ is justified in our case due to the low variation of the measured value (10th percentile: $0.71,90$ th percentile: 0.98 ) and due to the negligible impact of $\alpha_{\text {ap }}$ on the ambient extinction coefficient where the scattering is the clearly dominant part (e.g. taking 1 or 1.5 as a fixed value for $\alpha_{\text {ap }}$ would increase the ambient extinction coefficient only by a factor of 1.002 or 1.01 , respectively). $f(\mathrm{RH})$ was interpolated assuming a linear relationship. Time periods with $\mathrm{RH}>95 \%$ were ignored, due to the uncertainty in the parameterization of $f(\mathrm{RH})$ at very high $\mathrm{RH}$ values (e.g. $f(\mathrm{RH}) \rightarrow \infty$ for $\mathrm{RH} \rightarrow 100 \%) . \quad c_{p}=p(h) T_{0} / p_{0} T(h)$ accounts for pressure and temperature differences inside $\left(p_{0}\right.$, $\left.T_{0}\right)$ and outside $(p(h), T(h))$ the nephelometer. For the calculation of $p(h)$ the barometric formula was used, where $h$ is the height of the RH measurement. This is mainly of importance for the comparison to the MPI measurements where the measured extinction coefficient is a mean value for a varying layer height $(20-5000 \mathrm{~m})$. At the Cabauw tower, the temperature and dew point (from which the RH can be derived via the Magnus formula) are continuously measured at 10 , 20, 40, 80, 140, and $200 \mathrm{~m}$. For the MPI comparison the temperature and $\mathrm{RH}$ profiles were taken from the operational weather forecast model COSMO (based on assimilated data, see http://www.cosmo-model.org/). It was assumed that the aerosol type and concentration are constant with altitude and only RH is changing. Only the retrievals at the lowest height level of the remote sensing instruments were compared to insitu measurements.

\subsubsection{MAX-DOAS}

For comparison with the in-situ measurements, aerosol extinction coefficient from the lowermost layer of the MAXDOAS profiles from BIRA, IUPHD and JAMSTEC are used. BIRA and IUPHD retrievals use a layer thickness of $200 \mathrm{~m}$, whereas from the JAMSTEC retrieval with a layer height of $1 \mathrm{~km}$, an extinction coefficient representative for the lowermost $200 \mathrm{~m}$ has been estimated by assuming an exponentially decreasing extinction profile. In the MPI retrieval a mean aerosol extinction coefficient in the boundary layer is estimated by retrieving the layer height and the aerosol optical thickness. The $f(\mathrm{RH})$ value was calculated for each available RH measurements of the tower (for MPI taken from the COSMO model), and a mean value was then calculated using Eq. (10). For the correction factor $c_{p}$, the pressure was taken from ground based measurements (and taking the barometric height formula for the height dependency) and the temperature was measured next to the RH sensors (for MPI again the COSMO data was used). It should be pointed out that the comparison of the lowest MAX-DOAS extinction coefficient with in-situ measurements is of special interest since the MAX-DOAS retrieval has its highest sensitivity at the ground (Frieß et al., 2006) while LIDAR measurements are usually challenged with the overlap problem at low altitudes. In a recent study ( $\mathrm{Li}$ et al., 2010), good agreement was found between aerosol extinction coefficients retrieved from MAX-DOAS and surface in-situ measurements. MAXDOAS aerosol extinction coefficient profiles have only been compared in very few studies with other independent profiling techniques. Irie et al. $(2008,2009)$ made comparisons between lower-tropospheric vertical profiles retrieved from the JAMSTEC MAX-DOAS and coincident LIDAR observations at Tsukuba, Japan. They found reasonable agreement for layers of $0-1$ and $1-2 \mathrm{~km}$ to within $30 \%$ and $60 \%$, respectively, for most cases. However, these very few studies also show the need for further independent validation studies like the one presented here.

In Fig. 7 an example measurement of 24 June 2009 is seen. This day was characterized by almost entirely cloud free conditions in the morning and was classified as one of the golden days during CINDI (Roscoe et al., 2010). This is also reflected in the LIDAR measurement (Fig. 7a), which showed the appearance of cirrus clouds at around 10:00 a.m. and low level clouds at around 11:30 a.m. The agreement between MAX-DOAS and in-situ is good during the forenoon, which was characterized by high ambient RH values, which were decreasing until noon (see color code of ambient insitu values in Fig. $7 b-e)$; concurrently the extinction was decreasing within all measurements. From approximately 10:30 a.m. (12:00 p.m. for IUPHD) the MAX-DOAS and ambient in-situ values of $\sigma_{\text {ep }}$ were diverging. This was coincident with an increase of the planetary boundary layer height and the appearance of low level clouds (see LIDAR measurement in Fig. 7a), while the surface values of RH (between 0-200 m) stayed below $70 \%$. The comparison of the aerosol optical depth (AOD), which is the integral of $\sigma_{\text {ep }}$ over the vertical column, retrieved by the MAX-DOAS and measured by a Cimel sun photometer showed good agreement during the entire day, although this is just a columnar value being compared and gives no information on the true profile shape (further details in Frieß et al., 2011).

Figures 8 and 9 display the comparison of the entire data set, for the time periods given in Table 1. All MAX-DOAS instruments detect generally a higher extinction coefficient than the in-situ measurements. The slope of the applied bivariate linear regression (Cantrell, 2008; York et al., 2004) varies from 2.9 (IUPHD), 3.4 (JAMSTEC) to 3.4 (BIRA, with sun photometer (Cimel) used as input values). The MPI MAX-DOAS shows a lower slope (1.5), but has to be treated with care since the retrieval height varied and $\mathrm{RH}$ profiles were taken from a re-analyzed weather model (COSMO). All comparisons are well correlated $\left(R^{2}=0.62\right.$ to 0.78$)$. An 
Table 2. Results of an orthogonal linear regression (using weights) between ambient in-situ and MAX-DOAS extinction coefficients for the time periods given in Table 1. Values in parenthesis are for time periods when all four MAX-DOAS instruments were measuring in parallel.

\begin{tabular}{|c|c|c|c|c|c|}
\hline & BIRA with Cimel & BIRA with in-situ & IUPHD & JAMSTEC & MPI \\
\hline Slope & $3.4(2.9)$ & $2.7(2.4)$ & $2.9(2.2)$ & $3.4(2.6)$ & $1.5(1.2)$ \\
\hline Error slope & $0.06(0.08)$ & $0.04(0.06)$ & $0.05(0.06)$ & $0.06(0.09)$ & $0.08(0.2)$ \\
\hline Intercept & $-1.6 \times 10^{-5}\left(-2.4 \times 10^{-5}\right)$ & $-8.2 \times 10^{-6}\left(-1.3 \times 10^{-5}\right)$ & $-1.2 \times 10^{-5}\left(1.2 \times 10^{-5}\right)$ & $-2.9 \times 10^{-6}\left(1.4 \times 10^{-5}\right)$ & $4.6 \times 10^{-5}\left(4.3 \times 10^{-5}\right)$ \\
\hline Error intercept & $2 \times 10^{-6}\left(3 \times 10^{-6}\right)$ & $1 \times 10^{-6}\left(2 \times 10^{-6}\right)$ & $2 \times 10^{-6}\left(4 \times 10^{-6}\right)$ & $2 \times 10^{-6}\left(3 \times 10^{-6}\right)$ & $8 \times 10^{-6}\left(2 \times 10^{-5}\right)$ \\
\hline No. of points & $404(124)$ & $362(132)$ & $830(177)$ & $629(96)$ & $642(194)$ \\
\hline$R^{2}$ & $0.78(0.79)$ & $0.81(0.83)$ & $0.66(0.76)$ & $0.74(0.75)$ & $0.62(0.72)$ \\
\hline
\end{tabular}

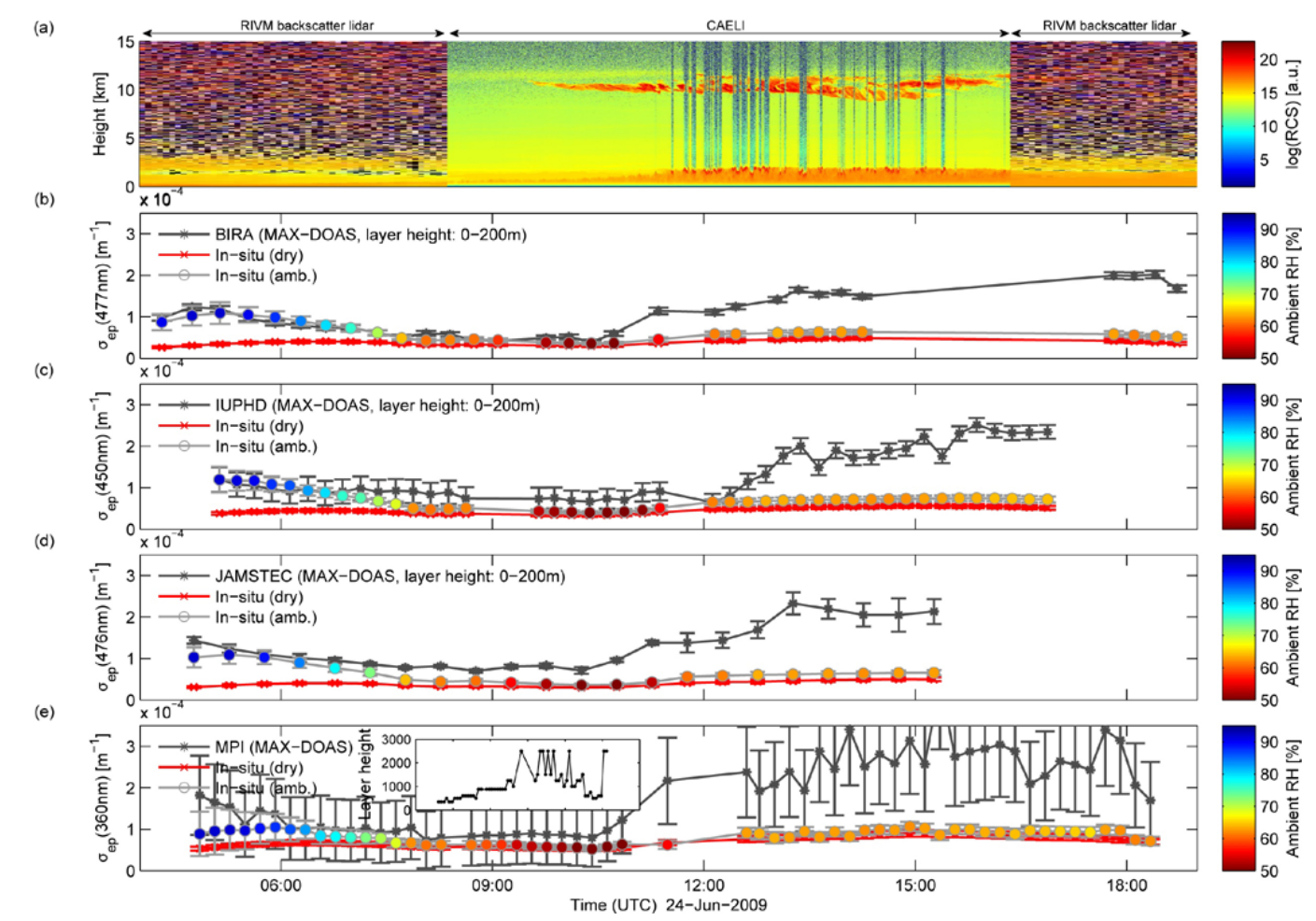

Fig. 7. Example day 24 June 2009 (golden day). Panel (a) Range corrected signal (RCS) at 1064 nm measured by the RIVM backscatter and the CAELI LIDAR. Panels (b)-(e) Time series of the aerosol extinction coefficient retrieved by MAX-DOAS instruments (black line) compared to in-situ measurements (red line: dry in-situ extinction coefficient, grey line: ambient value at the RH denoted in the color coded dots).

overview of the coefficients retrieved from the orthogonal linear fit and the correlation is found in Table 2. Slope and $R^{2}$ improve slightly if only identical time periods (when all four MAX-DOAS instruments were measuring at the same time) are being compared, although the number of comparable points is largely reduced (see Table 2). A distinct number of points show a good agreement and are located on the 1:1line. The color code in Fig. 8 reveals that these are times with a low aerosol optical depth (data from the AERONET sun photometer measurement, level 2.0). Figure 9 shows the same comparison, but with the planetary boundary layer (PBL) height as color code. The PBL height is measured by a ceilometer (Vaisala, Model LD-40; for details concerning the algorithm see de Haij et al., 2007, 2010). The points with better agreement show a low PBL height.

Figure 10 illustrates the comparison of the MPI measurement, where the layer height is kept variable during the retrieval. The agreement improves with decreasing layer height despite the assumptions that had to be made (well mixed aerosol layer, same aerosol type, RH from COSMO).

The error bars of the ambient in-situ extinction coefficient in Figs. 7-10 were derived from Gaussian error propagation assuming a $10 \%$ uncertainty of the nephelometer (Anderson et al., 1996) and a 12\% uncertainty of the MAAP (Petzold and Schönlinner, 2004). 

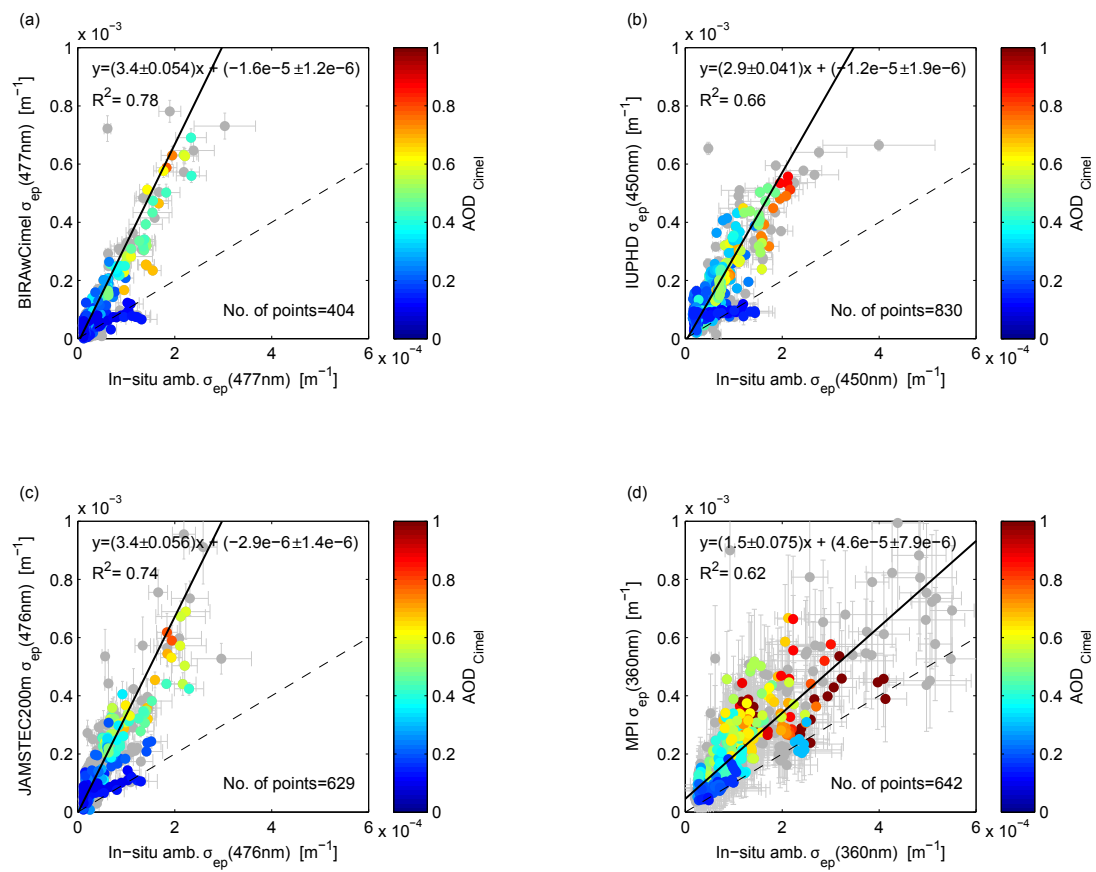

Fig. 8. Ambient extinction coefficient retrieved by MAX-DOAS vs. in-situ measurements brought to ambient conditions. The color code denotes the AOD measured by the Cimel sun photometer (AOD interpolated in accordance with the appropriate wavelength; grey points are times with no sun photometer measurements). The solid black line represents a bivariate linear regression including weights (with calculated uncertainty of slope and intercept). The dashed line is the 1:1-line.
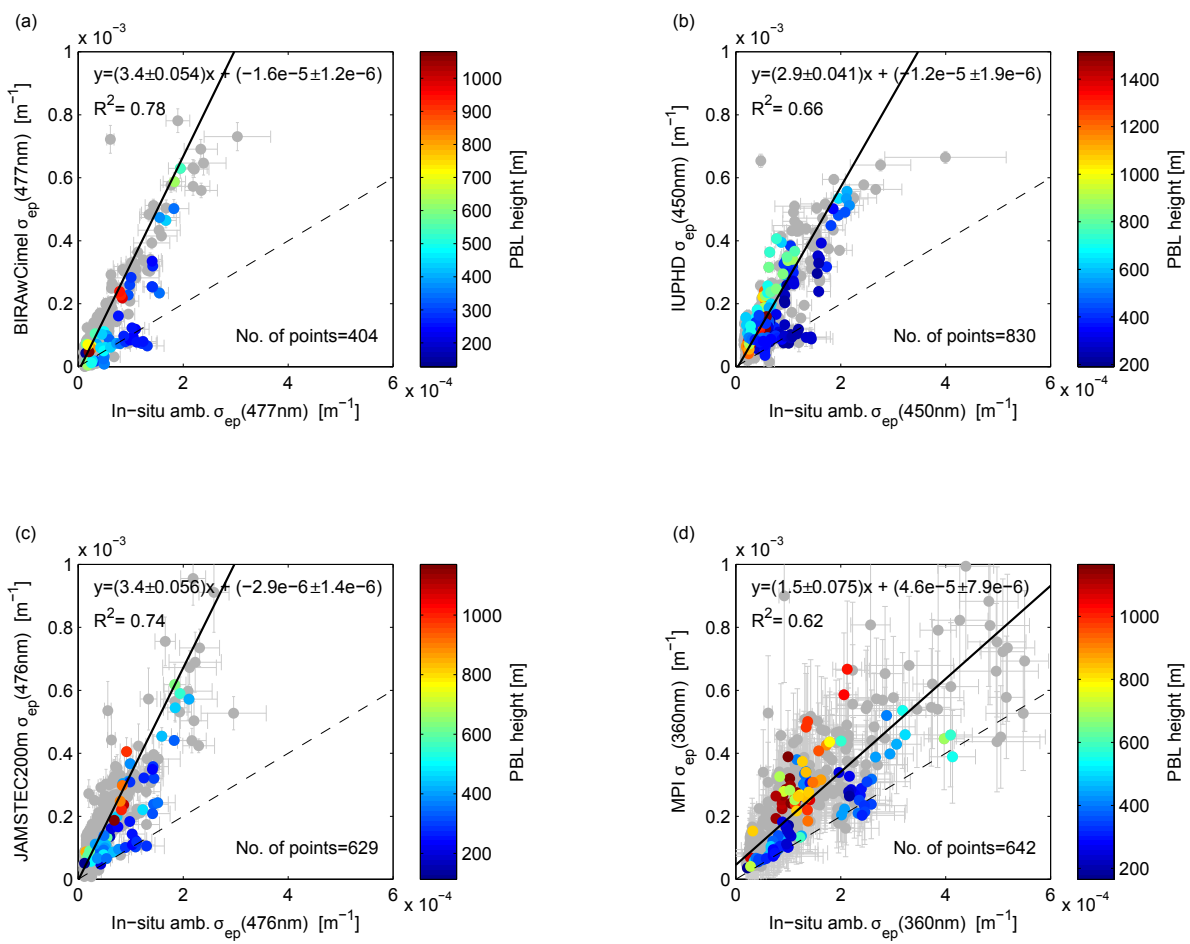

Fig. 9. Same as Fig. 8, but here the color code denotes the planetary boundary layer height measured by the ceilometer (grey points: no quality assured PBL data available). 

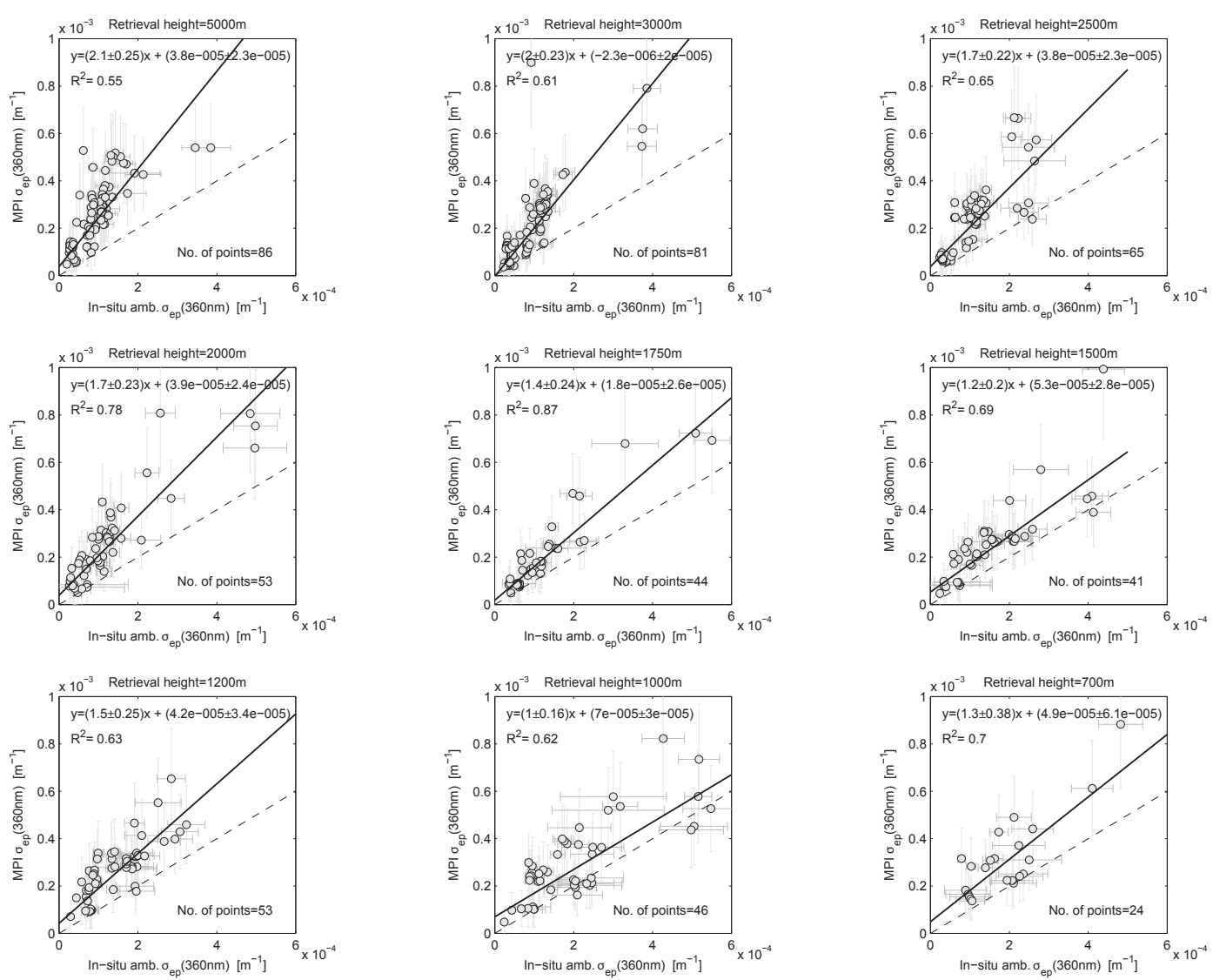

Fig. 10. Ambient extinction coefficient measured by the MPI MAX-DOAS instrument, where the layer height is kept variable during the MAX-DOAS retrieval vs. in-situ. The aerosol type is assumed to be constant within the layer (for the calculation of the in-situ $\sigma_{\mathrm{ep}}$, only the RH changes with height). The RH profiles are taken from assimilated COSMO data. Solid line represents a bivariate linear regression including weights (with calculated uncertainty of slope and intercept), dashed line is the 1:1-line.

For the BIRA and IUPHD retrieval the error bars represent the sum of the noise and smoothing error. Forward model errors were not considered here (Rodgers, 2000; Frieß et al., 2006; Clémer et al., 2010). For the JAMSTEC retrieval the errors have been quantified by the retrieval covariance matrix, which is defined to represent the sum of the smoothing error and the retrieval noise error (Rodgers, 2000). For the MPI retrieval so far no full error assessment was implemented, and the errors were assumed to be $0.25 \sigma_{\text {ep }}+0.05 \times 10^{-3} \mathrm{~m}^{-1}$.

As already mentioned, BIRA uses the values of the asymmetry factor and the single scattering albedo inverted from sun photometer measurements in their standard retrieval. The comparison improves if in-situ measurements (at ambient conditions) of the asymmetry factor and the single scattering albedo are taken as input parameters (see Table 2). This however can be caused by the large uncertainty of the single scattering albedo and the asymmetry factor retrieved from AERONET at low AOD.
The following hypotheses concerning the disagreement are being made. On the in-situ side:

- Particle losses due to impaction or diffusion in the inlet system

- Underestimation of the measured extinction due to the $\mathrm{PM}_{10}$ size cut

- Parameterization of $f(\mathrm{RH})$ (Eq. (8), large errors for $\mathrm{RH}>90 \%)$

On the MAX-DOAS side:

- BIRA, JAMSTEC, IUPHD: systematic overestimation of the lowest level $(0-200 \mathrm{~m})$. The most probable explanation for this finding is that due to the limited vertical resolution of the retrievals, the presence of aerosol at higher altitudes $(>200 \mathrm{~m})$ might result in an overestimation of the lowest level of $\sigma_{\text {ep }}$. In addition, in the case of an uplifted aerosol layer with a strong vertical gradient near the surface, the vertical resolution of about 


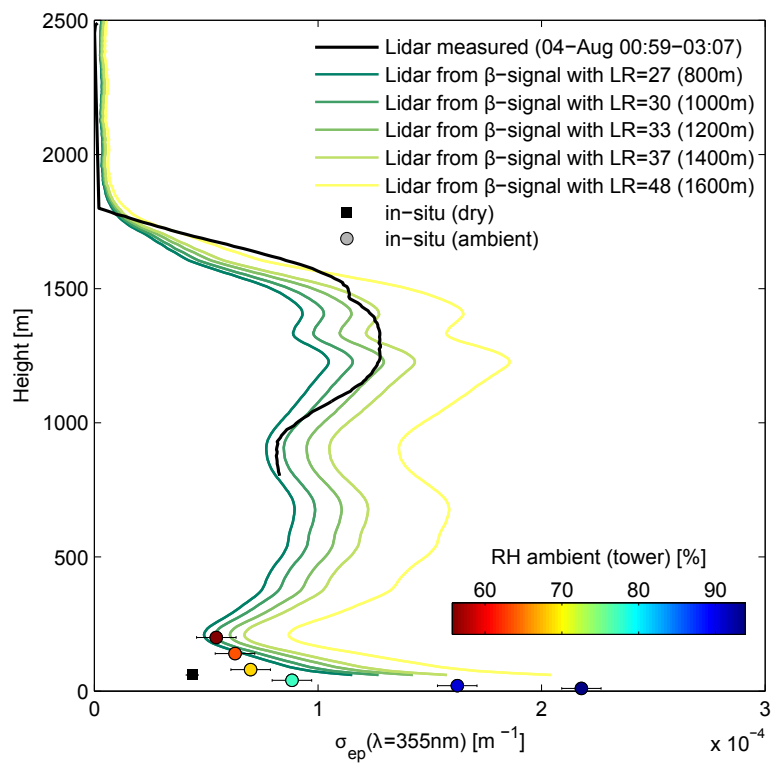

Fig. 11. Lidar and in-situ measurements of the aerosol extinction coefficient $\sigma_{\text {ep }}$ at $\lambda=355 \mathrm{~nm}$ (4 August 2009, 00:59-03:07). Black line: Direct LIDAR measurement of $\sigma_{\mathrm{ep}}$; Colored lines: $\sigma_{\text {ep }}$ calculated from the backscatter signal using measured LIDAR ratios (LR) obtained from mean values of different height levels $( \pm 100 \mathrm{~m})$; black square: $\sigma_{\text {ep }}$ measured in-situ at dry conditions; colored circles: $\sigma_{\text {ep }}$ brought to ambient conditions (color code denotes the ambient RH measured at the tower, error bars are retrieved via Gaussian error propagation).

$250 \mathrm{~m}$ near the surface will be insufficient and result in an overestimation of the surface value.

- Influence of the horizontal aerosol gradient, which might exhibit large variation

- Influence of clouds

The influence of clouds was tested by comparing only data points for which AERONET AOD measurements (level 2.0) were available (other time periods were excluded in the AERONET data processing due to the presence of clouds). No clear improvement could be observed; therefore the influence of clouds is believed not to be the main cause for this disagreement.

The smaller slope of the regression line for the MPI measurements could indicate that the coarser resolution with more simplified assumptions is a more robust retrieval. It should, however, also be noted that the scatter and the y-axis intercept for the MPI retrieval is larger than for the other retrievals.

The comparison was also tested against other parameters like the ambient $\mathrm{RH}$ (to check the validity of the $f(\mathrm{RH})$ parameterization), the aerosol mean diameter (to check for dependencies concerning the size dependent losses), the wind direction, and the single scattering albedo (to check for aerosol type dependencies). No clear dependency was found. With this and with the favorable results from the closure study in mind (Sect. 4.3), we assume that the in-situ measurements are not the main reason for the disagreement and only a certain percentage (possibly $<10-30 \%$ ) can be explained through errors in the in-situ data.

\subsubsection{LIDAR}

Due to the long averaging times, only 22 profiles (within the period 23 June-20 September, averaging time $1.85 \pm 0.5 \mathrm{~h}$ (mean \pm standard deviation) of the aerosol extinction coefficient measured by the CAELI LIDAR could be compared to the in-situ measurements. The aerosol extinction coefficient (at $355 \mathrm{~nm}$ ) can be measured directly using the Raman channel above approximately $750 \mathrm{~m}$. The backscatter signal, retrieved using the Raman method, starts at approximately $60 \mathrm{~m}$ and can be used to extrapolate the direct measurement of $\sigma_{\text {ep }}$ if an appropriate LIDAR ratio LR (Eq. 7) is assumed. Instead of an educated guess, the measured LR of the upper layers between 700 and $1700 \mathrm{~m}$ was determined (mean values for $200 \mathrm{~m}$ thick levels) and multiplied with the backscatter signal.

An example day is presented in Fig. 11. The extinction is directly measured above $\sim 750 \mathrm{~m}$ (black line). The LR of the upper layers increase with height from $L R=37$ to $L R=48$ (due to changing $\mathrm{RH}$ and/or aerosol type changes or lower signal to noise ratio). These values are used to calculate $\sigma_{\mathrm{ep}}$ by multiplying the backscatter signal with the LR. The in-situ values at dry (black square) and at ambient conditions at the RH measurement of the tower (color coded circles) are also shown. The large RH gradient results in a strong increase of $\sigma_{\text {ep }}$ concurrently determined indirectly from both the in-situ aerosol measurements and the LIDAR measurements.

The LR values are within the range as e.g. modeled by Ackermann (1998) for marine ( $\mathrm{LR}=\sim 10-25$ between $\mathrm{RH}=0-99 \%)$ or continental aerosol $(\mathrm{LR}=\sim 40-70$ between $\mathrm{RH}=0-99 \%)$ or as observed by Müller et al. (1997) for urban haze in central Europe ( $\mathrm{LR}=58 \pm 12$ ). As mentioned above, the LR depends besides the aerosol composition also strongly on the RH. To illustrate the effect of RH on the LR measured here, the LR of the individual layer versus the layer $\mathrm{RH}$ is shown in Fig. 12a. The RH-profiles were taken from a re-analyzed weather model (COSMO). One can observe that for most of the cases the LR increases with increasing RH, similar to the model results of Ackermann 1998 or the measurements of Salemink et al. (1984). Of course, also the aerosol type might change with altitude which can not be excluded here.

The LR of the lowest possible height level was multiplied with the mean backscatter coefficient measured between $(\sim 60-200 \mathrm{~m})$ to retrieve a mean extinction coefficient for the ground (see Eq. 7). In addition, the individual retrieved LR-RH-relationships (see Fig. 12a) were used to calculate (interpolate) the LR for the mean RH measured at the 
(a)

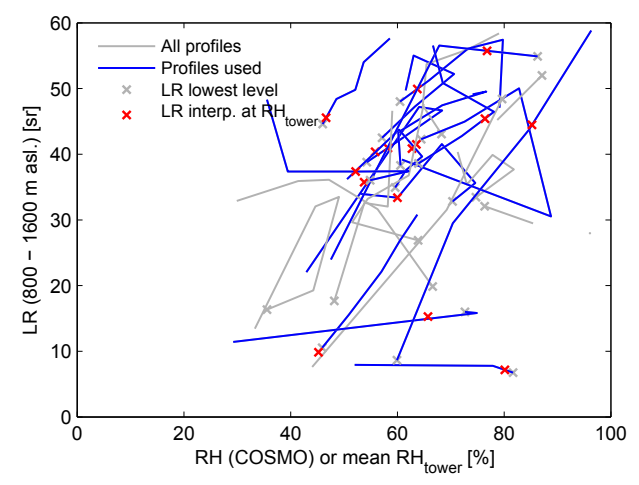

(b)

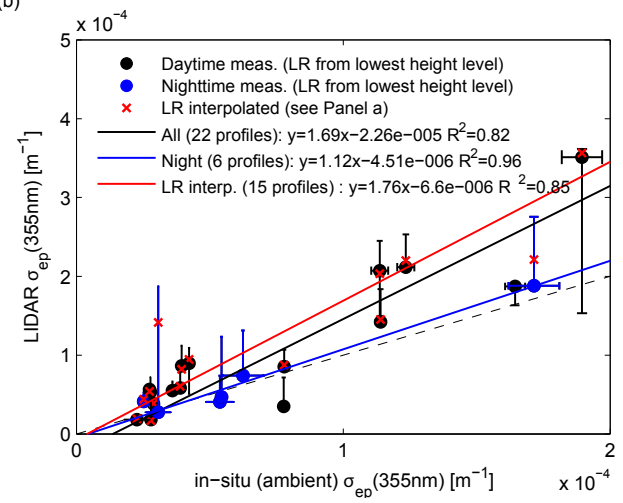

Fig. 12. Panel (a): The LIDAR ratio LR measured in 200-m altitude intervals between 700 and $1700 \mathrm{~m}$ versus the RH in the individual layer (taken from COSMO). Grey crosses denote the LR of the lowest layer, red crosses show the interpolated LR for the RH measured at the ground (mean 60-200 m). The profiles used to retrieve the interpolated value are shown in blue. Grey are all profiles (where no interpolation was possible or where no WetNeph measurements were available). Panel (b): Comparison of the extinction coefficient $\sigma_{\mathrm{ep}}$ at the ground retrieved from LIDAR vs. the in-situ values (mean for 60-200 m). Circular points denote the mean value if the LR from the lowest level is taken (black daytime measurements; blue nighttime measurements). Red crosses show the mean value if the LR interpolated to the ground RH is taken (see Panel a). The y-error bars give the range of the retrieved $\sigma_{\text {ep }}$ taking the measured minima and maxima LR of the upper layer. The $\mathrm{x}$-error bars give the calculated error in the ambient in-situ measurement. The solid lines represent linear orthogonal regressions (see legend).

ground. With this method only 15 profiles could be compared since the no extrapolation was performed. The result is shown in Fig. 12b. The error bars denote the range of the retrieved extinction coefficient taking the maximum and minimum value of the measured LR to calculate $\sigma_{\mathrm{ep}}$ at the ground.

Orthogonal linear regressions (without weights) revealed that the LIDAR retrieved $\sigma_{\text {ep }}$ were about $\sim 1.7-1.8$ higher compared to the ambient in-situ values. There is no large difference if the LR interpolated to the ground RH (instead of the LR from the lowest layer) is being used, which indicates that the LR of the lowest level has been a good estimate for the LR at the ground (at least for most of the cases). Both sets of $\sigma_{\text {ep }}$ are well correlated to the ambient in-situ values $\left(R^{2}=0.82-0.96\right)$. Nighttime measurements showed to have a better agreement (slope $1.12, R^{2}=0.96$ ) compared to daytime measurements, which might be due to lower noise in the LIDAR measurements during nighttime. However, this improvement has to be treated with care since only 6 profiles were measured during nighttime.

\section{Conclusions}

In this study, the influence of water uptake on the aerosol extinction coefficient was investigated during a 4-month campaign at the Cabauw field station (The Netherlands) using direct measurements of aerosol optical and micro-physical properties. While the scattering coefficient was measured as a function of RH, the absorption coefficient was measured dry and assumed not to change with RH. The scat- tering enhancement factor $f(\mathrm{RH})$ was found to be highly variable ( $f(\mathrm{RH})$ varied between $\sim 1.4$ and 3.8 at $\mathrm{RH}=85 \%$ ) and dependent on the air mass origin. Continental aerosol showed a lower scattering enhancement possibly due to anthropogenic pollution and lower sea salt content. Hysteresis was observed only during some very few events, when the air masses arrived directly from the oceans. The best quantity to estimate $f(\mathrm{RH})$ from other continuous in-situ measurements was found to be the hygroscopic growth factor measured e.g. by a H-TDMA. The use of the scattering Ångström exponent did not correlate well with $f(\mathrm{RH})$ due to the large variability in the chemical composition. This makes a simple prediction of $f(\mathrm{RH})$ at Cabauw, in contrast to other sites (e.g. Jungfraujoch), quite difficult. Here, continuous measurements of $f(\mathrm{RH})$ and/or better chemical composition measurements would be desirable to better relate dry measured values to the ambient ones. A closure study, which relied on the measured size distribution and the hygroscopic growth, showed the consistency of the aerosol in-situ measurements. The imaginary part of the retrieved complex refractive index was found to correlate well with the hygroscopic growth factor of the HTDMA, which means that more absorbing particles grow less. As a proof of concept, the in-situ measurements were compared with remote sensing data from MAX-DOAS and LIDAR measurements. A good correlation was found between in-situ and MAXDOAS measurements. For certain cases (low AOD and low PBL height) good agreement was found, but for most of the time MAX-DOAS retrieved a $\sim 1.5-3.4$ higher extinction coefficient. Differences could have been caused by e.g. particle 
losses in the inlet system (all remote-sensing instruments were measuring generally higher extinction) or by the fact that the limited vertical resolution of the MAX-DOAS retrieval overestimated the extinction in the lowest layer when lofted layers were present. In addition, the MAX-DOAS retrieval could have been influenced by the horizontal aerosol gradient, which could have exhibited large variations. The smaller slope of the regression line for the MPI measurements could indicate that the coarser resolution with more simplified assumptions is a more robust MAX-DOAS aerosol retrieval. Lidar and in-situ comparison found to be in better agreement, although the direct measurement of the ambient extinction coefficient started from an altitude above $750 \mathrm{~m}$. Extrapolation with the backscatter signal showed a good correlation $\left(R^{2}=0.82-0.85\right)$ and a higher extinction compared to in-situ (slope of 1.69-1.76), which improved (slope of $1.12, R^{2}=0.96$ ) if only nighttime measurements were compared.

Acknowledgements. We thank Jacques Warmer and the staff of KNMI at the CESAR site for providing an excellent service during our campaign. We thank the CINDI local organization team at KNMI, in particular Ankie Piters, Mark Kroon, and Jennifer Hains, for facilitating this very successful campaign. We gratefully acknowledge Henk Klein-Baltink (KNMI) for providing the ceilometer data. We also gratefully acknowledge the easy access of the meteorological data used in this work via http://www.cesar-observatory.nl. We thank Rahel Fierz (PSI) for valuable discussions. Many thanks to Michel Tinquely (PSI) for helping out with the COSMO data, which was provided by the Swiss Federal Office of Meteorology and Climatology (MeteoSwiss). NILU and especially Ann Mari Fjæraa are gratefully acknowledged for providing the air mass trajectories. Many thanks to A. Rozanov from the Institute of Environmental Physics, University of Bremen, for providing the SCIATRAN radiative transfer model to IUPHD. Hitoshi Irie thanks H. Takashima, Y. Kanaya, and PREDE, Co., Ltd for their technical assistance in developing and operating the MAX-DOAS instrument. Observation by JAMSTEC was supported by the Japan EOS Promotion Program of the Ministry of Education, Culture, Sports, Science and Technology (MEXT), and by the Global Environment Research Fund (S-7) of the Japanese Ministry of the Environment. Katrijn Clémer (BIRAIASB) was financially supported by the AGACC project (contract SD/AT/10A) funded by the Belgian Federal Science Policy Office. This work was financially supported by the ESA Climate Change Initiative Aerosol_cci (ESRIN/Contract No. 4000101545/10/I-AM) and by the EC-projects Global Earth Observation and Monitoring (GEOmon, contract 036677) and European Supersites for Atmospheric Atmospheric Aerosol Research (EUSAAR, contract 026140).

Edited by: A. Petzold

\section{References}

Ackermann, J.: The extinction-to-backscatter ratio of tropospheric aerosols: a numerical study, J. Atmos. Ocean. Tech., 15, 10431050, 1998.

Anderson, T., Covert, D., Marshall, S., Laucks, M., Charlson, R., Waggoner, A., Ogren, J., Caldow, R., Holm, R., Quant, F., Sem, G., Wiedensohler, A., Ahlquist, N., and Bates, T.: Performance characteristics of a high-sensitivity, three-wavelength, total scatter/backscatter nephelometer, J. Atmos. Oceanic Technol., 13, 967-986, 1996.

Ansmann, A., Wandinger, U., Riebesell, M., Weitkamp, C., and Michaelis, W.: Independent measurement of extinction and backscatter profiles in cirrus clouds by using a combined Raman elastic-backscatter lidar, Appl. Opt., 31, 7113-7131, 1992.

Apituley, A., Wilson, K.M., Potma, C., Volten, H., and de Graaf, M.: Performance Assessment and Application of Caeli - A highperformance Raman lidar for diurnal profiling of Water Vapour, Aerosols and Clouds, Proceedings of the 8th International Symposium on Tropospheric Profiling, 19-23 October 2009, Delft, The Netherlands, 2009.

Bond, T. C. and Bergstrom, R. W.: Light absorption by carbonaceous particles: an investigative review, Aerosol Sci. Technol., 40(1), 27-67, 2006.

Birmili, W., Stopfkuchen, K., Hermann, M., Wiedensohler, A., and Heintzenberg, J.: Particle penetration through a $300 \mathrm{~m}$ inlet pipe for sampling atmospheric aerosols from a tall meteorological tower, Aerosol Sci. Technol., 41, 811-817, 2007.

Cantrell, C. A.: Technical Note: Review of methods for linear leastsquares fitting of data and application to atmospheric chemistry problems, Atmos. Chem. Phys., 8, 5477-5487, doi:10.5194/acp8-5477-2008, 2008.

Carrico, C. M., Kus, P., Rood, M. J., Quinn, P. K., and Bates, T. S.: Mixtures of pollution, dust, sea salt, and volcanic aerosol during ACE-Asia: radiative properties as a function of relative humidity, J. Geophys. Res., 108(D23), 8650, doi:10.1029/2003JD003405, 2003.

Clarke, A. D., Howell, S., Quinn, P. K., Bates, T. S., Ogren J. A., Andrews, E., Jefferson, A., Massling, A., Mayol-Bracero, O., Maring, H., Savoie, D., and Cass, G.: INDOEX aerosol: A comparison and summary of chemical, microphysical, and optical properties observed from land, ship, and aircraft, J. Geophys. Res., 107, 8033, doi:803310.1029/2001JD000572, 2002.

Clémer, K., Van Roozendael, M., Fayt, C., Hendrick, F., Hermans, C., Pinardi, G., Spurr, R., Wang, P., and De Mazière, M.: Multiple wavelength retrieval of tropospheric aerosol optical properties from MAXDOAS measurements in Beijing, Atmos. Meas. Tech., 3, 863-878, doi:10.5194/amt-3-863-2010, 2010.

Collaud Coen, M., Weingartner, E., Apituley, A., Ceburnis, D., Fierz-Schmidhauser, R., Flentje, H., Henzing, J. S., Jennings, S. G., Moerman, M., Petzold, A., Schmid, O., and Baltensperger, U.: Minimizing light absorption measurement artifacts of the Aethalometer: evaluation of five correction algorithms, Atmos. Meas. Tech., 3, 457-474, doi:10.5194/amt-3-457-2010, 2010.

de Haij, M., Klein Baltink, H., and Wauben, W.: Continuous mixing layer height determination using the LD40-ceilometer: a feasibility study, KNMI Scientific Report WR 2007-01, De Bilt, The Netherlands, 2007.

de Haij, M., Wauben, W., Klein Baltink, H., and Apituley, A.: Determination of the mixing layer height by a ceilometer, Proceed- 
ings of the 8th International Symposium on Tropospheric Profiling, 19-23 October, Delft, The Netherlands, edited by: Apituley, A., Russchenberg, H. W. J., Monna, W. A. A., ISBN 978-906960-233-2, 2010.

Deutschmann, T. and Wagner, T.: TRACY-II Users manual, available online at: http://joseba.mpch-mainz.mpg.de/ Strahlungstransport.htm, 2008.

Ehn, M., Petäjä, T., Aufmhoff, H., Aalto, P., Hämeri, K., Arnold, F., Laaksonen, A., and Kulmala, M.: Hygroscopic properties of ultrafine aerosol particles in the boreal forest: diurnal variation, solubility and the influence of sulfuric acid, Atmos. Chem. Phys., 7, 211-222, doi:10.5194/acp-7-211-2007, 2007.

Ferrare, R. A., Melfi, S. H., Whiteman, D. N., Evans, K. D., and Leifer, R.: Raman lidar measurements of aerosol extinction and backscattering, 1. Methods and comparisons, J. Geophys. Res., 103(D16), 19663-19672, 1998.

Fierz-Schmidhauser, R., Zieger, P., Gysel, M., Kammermann, L., DeCarlo, P. F., Baltensperger, U., and Weingartner, E.: Measured and predicted aerosol light scattering enhancement factors at the high alpine site Jungfraujoch, Atmos. Chem. Phys., 10, 23192333, doi:10.5194/acp-10-2319-2010, 2010a.

Fierz-Schmidhauser, R., Zieger, P., Vaishya, A., Monahan, C., Bialek, J., O’Dowd, C.D., Jennings, S. G., Baltensperger, U., and Weingartner, E.: Light scattering enhancement factors in the marine boundary layer (Mace Head, Ireland), J. Geophys. Res., 115, D20204, doi:10.1029/2009JD013755, 2010b.

Fierz-Schmidhauser, R., Zieger, P., Wehrle, G., Jefferson, A., Ogren, J. A., Baltensperger, U., and Weingartner, E.: Measurement of relative humidity dependent light scattering of aerosols, Atmos. Meas. Tech., 3, 39-50, doi:10.5194/amt-3-392010, 2010c.

Fitzgerald, J. W., Hoppel, W. A., and Vietti, M. A.: The size and scattering coefficient of urban aerosol particles at Washington, DC as a function of relative humidity, J. Atmos. Sci., 39, 18381852, 1982.

Freudenthaler, V.: The Telecover Test: A quality assurance tool for the optical part of a lidar system, available online at: http://www.meteo.physik.uni-muenchen.de $/ \sim$ st 212 fre/ ILRC24/index.html, Proc. of the 24th ILRC, Boulder, Colorado, USA, 23-27 June 2008.

Frieß, U., Monks, P. S., Remedios, J. J., Rozanov, A., Sinreich, R., Wagner, T., and Platt, U.: MAX-DOAS $\mathrm{O}_{4}$ measurements: A new technique to derive information on atmospheric aerosols: 2. Modeling studies, J. Geophys. Res., 111, D14203, doi:10.1029/2005JD006618, 2006.

Frieß, U., Clémer, K., Irie, H., Vlemmix, T., Wagner, T., Wittrock, F., Yilmaz, S., Zieger, P., and Apituley, A.: Intercomparison of MAX-DOAS aerosol profile retrieval algorithms during the CINDI campaign, Atmos. Meas. Tech. Discuss., in preparation, 2011.

Gysel, M., McFiggans, G., and Coe, H.: Inversion of tandem differential mobility analyser (TDMA) measurements, J. Aerosol Sci., 40, 134-151, doi:10.1016/j.jaerosci.2008.07.013, 2009.

Heckel, A., Richter, A., Tarsu, T., Wittrock, F., Hak, C., Pundt, I., Junkermann, W., and Burrows, J. P.: MAX-DOAS measurements of formaldehyde in the Po-Valley, Atmos. Chem. Phys., 5, 909918, doi:10.5194/acp-5-909-2005, 2005.

Hess, M. P., Koepke, P., and Schultz, I.: Optical properties of aerosols and clouds: The software package OPAC, Bull. Mete- orol. Soc., 79, 831-844, 1998.

Holben, B. N., Eck, T. F., Slutsker, I., Tanre, D., Buis, J. P., Setzer, A., Vermote, E., Reagan, J. A., Kaufman, Y. J., Nakajima, T., Lavenu, F., Jankowiak, I., and Smimov, A.: AERONET -A federated instrument network and data archive for aerosol characterization, Remote Sens. Environ., 66(1), 1-16, 1998.

Hönninger, G. and Platt, U.: Observations of $\mathrm{BrO}$ and its vertical distribution during surface ozone depletion at Alert, Atmos. Environ., 36, 2481-2490, 2002.

Hönninger, G., von Friedeburg, C., and Platt, U.: Multi axis differential optical absorption spectroscopy (MAX-DOAS), Atmos. Chem. Phys., 4, 231-254, doi:10.5194/acp-4-231-2004, 2004.

Irie, H., Kanaya, Y., Akimoto, H., Iwabuchi, H., Shimizu, A., and Aoki, K.: First retrieval of tropospheric aerosol profiles using MAX-DOAS and comparison with lidar and sky radiometer measurements, Atmos. Chem. Phys., 8, 341-350, doi:10.5194/acp-8341-2008, 2008.

Irie, H., Kanaya, Y., Akimoto, H., Iwabuchi, H., Shimizu, A., and Aoki, K.: Dual-wavelength aerosol vertical profile measurements by MAX-DOAS at Tsukuba, Japan, Atmos. Chem. Phys., 9, 2741-2749, doi:10.5194/acp-9-2741-2009, 2009.

Iwabuchi, H.: Efficient Monte Carlo methods for radiative transfer modeling, J. Atmos. Sci., 63(9), 2324-2339, 2006.

Köhler, H.: The nucleus and growth of hygroscopic droplets, Trans. Faraday Soc., 32, 1152-1161, 1936.

Kotchenruther, R. A. and Hobbs, P. V.: Humidification factors of aerosols from biomass burning in Brazil, J. Geophys. Res., 103(D24), 32081-32089, 1998.

Leser, H., Hönninger, G., and Platt, U.: MAX-DOAS measurements of $\mathrm{BrO}$ and $\mathrm{NO}_{2}$ in the marine boundary layer, Geophys. Res. Lett., 30(10), 1537, doi:10.1029/2002GL015811, 2003.

Li, X., Brauers, T., Shao, M., Garland, R. M., Wagner, T., Deutschmann, T., and Wahner, A.: MAX-DOAS measurements in southern China: retrieval of aerosol extinctions and validation using ground-based in-situ data, Atmos. Chem. Phys., 10, 20792089, doi:10.5194/acp-10-2079-2010, 2010.

Liu, B. Y. H., Pui, D. Y. H., Whitby, K. T., Kittelson, D. B., Kousaka, Y., and McKenzie, R. L.: Aerosol mobility chromatograph - new detector for sulfuric-acid aerosols, Atmos. Environ., 12, 99-104, 1978.

Ming, Y. and Russell, L.: Predicted hygroscopic growth of sea salt aerosol, J. Geophys. Res., 106(D22), 28259-28274, 2001.

Morgan, W. T., Allan, J. D., Bower, K. N., Esselborn, M., Harris, B., Henzing, J. S., Highwood, E. J., Kiendler-Scharr, A., McMeeking, G. R., Mensah, A. A., Northway, M. J., Osborne, S., Williams, P. I., Krejci, R., and Coe, H.: Enhancement of the aerosol direct radiative effect by semi-volatile aerosol components: airborne measurements in North-Western Europe, Atmos. Chem. Phys., 10, 8151-8171, doi:10.5194/acp-10-8151-2010, 2010.

Müller, D., Ansmann, A., Mattis, I., Tesche, M., Wandinger, U., Althausen, D., and Pisani, G.: Aerosol-type-dependent lidar ratios observed with Raman lidar, J. Geophys. Res., 112(D16202), 1-11, 1997.

Müller, T., Henzing, J. S., de Leeuw, G., Wiedensohler, A., Alastuey, A., Angelov, H., Bizjak, M., Collaud Coen, M., Engström, J. E., Gruening, C., Hillamo, R., Hoffer, A., Imre, K., Ivanow, P., Jennings, G., Sun, J. Y., Kalivitis, N., Karlsson, H., Komppula, M., Laj, P., Li, S.-M., Lunder, C., Marinoni, A., Mar- 
tins dos Santos, S., Moerman, M., Nowak, A., Ogren, J. A., Petzold, A., Pichon, J. M., Rodriquez, S., Sharma, S., Sheridan, P. J., Teinilä, K., Tuch, T., Viana, M., Virkkula, A., Weingartner, E., Wilhelm, R., and Wang, Y. Q.: Characterization and intercomparison of aerosol absorption photometers: result of two intercomparison workshops, Atmos. Meas. Tech., 4, 245-268, doi:10.5194/amt-4-245-2011, 2011.

Nessler, R., Weingartner, E., and Baltensperger, U.: Adaptation of dry nephelometer measurements to ambient conditions at the Jungfraujoch, Environ. Sci. Technol., 39, 2219-2228, 2005a.

Nessler, R., Weingartner, E., and Baltensperger, U.: Effect of humidity on aerosol light absorption and its implications for extinction and the single scattering albedo illustrated for a site in the lower free troposphere, J. Aerosol Sci., 36, 958-972, 2005b.

Petters, M. D. and Kreidenweis, S. M.: A single parameter representation of hygroscopic growth and cloud condensation nucleus activity, Atmos. Chem. Phys., 7, 1961-1971, doi:10.5194/acp-71961-2007, 2007.

Petzold, A. and Schönlinner, M.: Multi-angle absorption photometry - a new method for the measurement of aerosol light absorption and atmospheric black carbon, J. Aerosol Sci., 35, 421-441, 2004.

Philippin, S., Laj, P., Putaud, J.-P., Wiedensohler, A., de Leeuw, G., Fjaeraa, A. M., Platt, U., Baltensperger, U., Fiebig, M.: EUSAAR - An unprecedented network of aerosol observation in Europe. Earozoru Kenkyu, JAAST, 24(2), 78-83, 2009.

Piters, A., Hains, J., Boersma, F., Kroon, M., Wittrock, F., van Roozendael, M.: The Cabauw Intercomparison campaign for Nitrogen Dioxide Measuring Instruments (CINDI), June/July 2009, The Netherlands, Atmos. Meas. Tech. Discuss., in preparation, 2010.

Platt, U. and Stutz, J.: Differential Optical Absorption Spectroscopy: Principles and Applications, Springer-Verlag, Berlin, Germany, 2008.

Rodgers, C. D.: Inverse Methods for Atmospheric Sounding: Theory and Practice, Ser. Atmos. Oceanic Planet. Phys., vol. 2, F. W. Taylor, World Sci., Hackensack, NY, USA, 2000.

Roscoe, H. K., Van Roozendael, M., Fayt, C., du Piesanie, A., Abuhassan, N., Adams, C., Akrami, M., Cede, A., Chong, J., Clmer, K., Friess, U., Gil Ojeda, M., Goutail, F., Graves, R., Griesfeller, A., Grossmann, K., Hemerijckx, G., Hendrick, F., Herman, J., Hermans, C., Irie, H., Johnston, P. V., Kanaya, Y., Kreher, K., Leigh, R., Merlaud, A., Mount, G. H., Navarro, M., Oetjen, H., Pazmino, A., Perez-Camacho, M., Peters, E., Pinardi, G., Puentedura, O., Richter, A., Schnhardt, A., Shaiganfar, R., Spinei, E., Strong, K., Takashima, H., Vlemmix, T., Vrekoussis, M., Wagner, T., Wittrock, F., Yela, M., Yilmaz, S., Boersma, F., Hains, J., Kroon, M., Piters, A., and Kim, Y. J.: Intercomparison of slant column measurements of $\mathrm{NO}_{2}$ and $\mathrm{O}_{4}$ by MAX-DOAS and zenith-sky UV and visible spectrometers, Atmos. Meas. Tech., 3, 1629-1646, doi:10.5194/amt-3-1629-2010, 2010.

Rozanov, A., Rozanov, V., and Burrows, J. P.: A numerical radiative transfer model for a spherical planetary atmosphere: combined differential-integral approach involving the Picard iterative approximation, J. Quant. Spec. Rad. Trans., 69, 491-512, 2001.

Russchenberg, H. W. J., Bosveld, F., Swart, D. P. J., ten Brink, H., de Leeuw, G., Uijlenhoet, R., Arbesser-Rastburg, B., van der Marel, H., Ligthart, L., Boers, R., and Apituley, A.: Ground- based atmospheric remote sensing in The Netherlands; European outlook, IEICE Transactions on Communications, E88B(6), 2252-2258, doi:10.1093/ietcom/e88-b.6.2252, 2005.

Salemink, H. W. M., Schotanus, P., and Bergwerff, J. B.: Quantitative lidar at $532 \mathrm{~nm}$ for vertical extinction profiles and the effect of relative humidity, Appl. Phys., 34, 187-189, 1984.

Sheridan, P. J., Delene, D. J., and Ogren, J. A.: Four years of continuous surface aerosol measurements from the Department of Energy's Atmospheric Radiation Program Southern Great Plains Cloud and Radiation Testbed site, J. Geophys. Res., 106, 2073520747, 2001.

Sinreich, R., Frieß, U., Wagner, T., and Platt, U.: Multi axis differential optical absorption spectroscopy (MAX-DOAS) of gas and aerosol distributions, Faraday Discuss., 130, 153-164, doi:10.1039/b419274, 2005.

Sjogren, S., Gysel, M., Weingartner, E., Baltensperger, U., Cubison, M. J., Coe, H., Zardini, A. A., Marcolli, C., Krieger, U. K., and Peter, T.: Hygroscopic growth and water uptake kinetics of twophase aerosol particles consisting of ammonium sulfate, adipic and humic acid mixtures, J. Aerosol Sci., 38, 157-171, 2007.

Spurr, R.: LIDORT and VLIDORT: Linearized pseudo-spherical scalar and vector discrete ordinate radiative transfer models for use in remote sensing retrieval problems, Light Scattering Reviews, Volume 3, edited by: Kokhanovsky, A., Springer Berlin Heidelberg, Germany, 229-275, 2008.

Stohl, A. and Seibert, P.: Accuracy of trajectories as determined from the conservation of meteorological tracers, Q. J. Roy. Meteorol. Soc., 124, 1465-1484, 1998.

Stohl, A., Wotawa, G., Seibert, P., and Kromp-Kolb, H.: Interpolation errors in wind fields as a function of spatial and temporal resolution and their impact on different types of kinematic trajectories, J. Appl. Meteorol., 34, 2149-2165, 1995.

Sundström , A.-M., Nousiainen, T., and Petäjä, T.: On the quantitative low-level aerosol measurements using ceilometer-type lidar, J. Atmos. Ocean. Technol., 26, 2340-2352, 2009.

Swietlicki, E., Hansson, H. C., Hameri, K., Svenningsson, B., Massling, A., McFiggans, G., McMurry, P. H., Petaja, T., Tunved, P., Gysel, M., Topping, D., Weingartner, E., Baltensperger, U., Rissler, J., Wiedensohler, A., and Kulmala, M.: Hygroscopic properties of submicrometer atmospheric aerosol particles measured with H-TDMA instruments in various environments - a review, Tellus, 60B, 432-469, 2008.

Van Roozendael, M., Fayt, C., Post, P., Hermans, C., and Lambert, J.-C.: Retrieval of $\mathrm{BrO}$ and $\mathrm{NO}_{2}$ from UV-Visible Observations, in: Sounding the troposphere from space: a new era for atmospheric chemistry, Springer-Verlag, ISBN 3-540-40873-8, edited by: Borell, P., Borrell, P. M., Burrows, J. P., and Platt, U., 2003.

Voss, K. J., Welton, J. E. J., Quinn, P. K., Frouin, R., Miller, M., and Reynolds, R. M.: Aerosol optical depth measurements during the Aerosols99 experiment, J. Geophys. Res., 106(D18), 2081120819, 2001.

Wagner, T., Dix, B., Friedeburg, v.C., Frieß, U., Sanghavi, S., Sinreich, R., and Platt, U.: MAX-DOAS $\mathrm{O}_{4}$ measurements: A new technique to derive information on atmospheric aerosols Principles and information content, J. Geophys. Res., 109, D22205, doi:10.1029/2004JD004904, 2004.

Wagner, T., Deutschmann, T., and Platt, U.: Determination of aerosol properties from MAX-DOAS observations of the Ring effect, Atmos. Meas. Tech., 2, 495-512, doi:10.5194/amt-2-495- 
2009, 2009.

Wagner, T., Beirle, S., Brauers, T., Deutschmann, T., Frieß, U., Hak, C., Halla, J. D., Heue, K. P., Junkermann, W., Li, X., Mettendorf, K.-U., Platt, U., and Pundt, I.: Inversion of tropospheric profiles of aerosol extinction and $\mathrm{HCHO}$ and $\mathrm{NO}_{2}$ mixing ratios from MAX-DOAS observations in Milano in summer 2003 and comparison with independent data sets, in preparation, 2011.

Wang, W., Rood, M. J., Carrico, C. M., Covert, D. S., Quinn, P. K., and Bates, T. S.: Aerosol optical properties along the northeast coast of North America during the New England Air Quality Study - Intercontinental Transport and Chemical Transformation 2004 campaign and the influence of aerosol composition, J. Geophys. Res., 112, D10S23, doi:10.1029/2006JD007579, 2007.

Weingartner, E., Burtscher, H., and Baltensperger, U.: Hygroscopic properties of carbon and diesel soot particles, Atmos. Environ., 31(15), 2311-2327, 1997.

Weingartner, E., Saathoff, H., Schnaiter, M., Streit, N., Bitnar, B., and Baltensperger, U.: Absorption of light by soot particles: Determination of the absorption coefficient by means of aethalometers, J. Aerosol Sci., 34, 1445-1465, 2003.

Winklmayr, W., Reischl, G., Lindner, A., and Berner, A.: A new electromobility spectrometer for the measurement of aerosol size distributions in the size range from 1 to $1000 \mathrm{~nm}$, J. Aerosol Sci., 22(3), 289-296, doi:10.1016/S0021-8502(05)80007-2, 1991.
Wittrock, F., Oetjen, H., Richter, A., Fietkau, S., Medeke, T., Rozanov, A., and Burrows, J. P.: MAX-DOAS measurements of atmospheric trace gases in Ny-Ålesund - Radiative transfer studies and their application, Atmos. Chem. Phys., 4, 955-966, doi:10.5194/acp-4-955-2004, 2004.

WMO/GAW: Aerosol Measurement Procedures Guidelines and Recommendations, GAW Report No. 153, World Meteorological Organization Global Atmosphere Watch, Geneva, Switzerland, 2003.

Yan, P., Pan, X. L., Tang, J., Zhou, X. J., Zhang, R. J., and Zeng, L. M.: Hygroscopic growth of aerosol scattering coefficient: a comparative analysis between urban and suburban sites at winter in Beijing, Particuology, 7, 52-60, 2009.

York, D., Evensen, N. M., Lopez Martinez, M., and De Basabe Delgado, J.: Unified equations for the slope, intercept, and standard errors of the best straight line, Am. J. Phys., 72(3), 367-375, 2004.

Zieger, P., Fierz-Schmidhauser, R., Gysel, M., Ström, J., Henne, S., Yttri, K. E., Baltensperger, U., and Weingartner, E.: Effects of relative humidity on aerosol light scattering in the Arctic, Atmos. Chem. Phys., 10, 3875-3890, doi:10.5194/acp-10-38752010, 2010. 